\title{
A Serious Game to Improve Engagement with Web Accessibility
}

Guidelines

Fotios Spyridonis ${ }^{\mathrm{a}}$ and Damon Daylamani-Zad ${ }^{\mathrm{a}}$

aSchool of Computing and Mathematical Sciences, University of Greenwich, Park Row, London, United Kingdom

Email address: 르.Spyridonis@greenwich.ac.uk and ㅁD.D.Zad@greenwich.ac.uk

This is the Author's Original Manuscript of an article published by Taylor \& Francis in Behaviour \& Information Technology on 07 Jan 2020, available online: http://www.tandfonline.com/doi/full/10.1080/0144929X.2019.1711453" 


\begin{abstract}
Designers are often faced with the challenge of following web accessibility guidelines that are complex and ambiguous, and therefore hard to use. This is evidenced by the low percentage of public websites that comply fully with web accessibility standards worldwide. Lack of engagement among designers to follow established web accessibility guidelines is often accounted for this issue. In this paper, we address designers' lack of engagement through a serious game called GATE which is based on the Web Content Accessibility Guidelines (WCAG). We followed a User-Centred approach by identifying user types of designers through an online survey. We then mapped these user types and the WCAG to relevant game mechanics. The resulting game was evaluated with designers for its perceived effectiveness, user engagement, and user satisfaction using a mixed methods approach. Our results demonstrate the potential of GATE which offers designers an innovative and engaging solution towards the wider adoption of web accessibility guidelines.
\end{abstract}

\title{
Keywords
}

Human Computer Interaction, Accessibility, User engagement, Serious Games, User modelling, Web design 


\section{Introduction}

There is a growing recognition of the importance of designing for accessibility over the last years. This is underpinned by legal drivers such as Section 508 of the 1998 Rehabilitation Act in the USA (Section508.gov, 1998) and the Equality Act of 2010 in the UK (UK Government, 2010). Accessibility design is an essential part of the design and development process of Information and Communication Technologies (ICT) and it is a concept that designers need to learn and apply in their practice. This in turn can prove to be beneficial for all involved parties, as accessible products are $35 \%$ more usable by everyone and are typically cheaper to run and maintain (AbilityNet, 2017). However, a flagship investigation by the Disability Rights Commission (2004) identified that only $19 \%$ of the 1,000 UK Web sites examined complied with the Web Content Accessibility Guidelines (WCAG). In a seminal article that brought WCAG to the forefront, Clark (2006) discussed that there are concerns with WCAG, especially with regards to its documentation size and its inscrutable language that can lead to their limited adoption.

In response to the need to identify better means to engage and motivate users, serious games have quickly become an established practice. The motivation behind leveraging serious games is typically related to improving education and training, employee engagement, and motivation and wellness, to name but just a few examples. However, the use of serious games to help designers better engage with the WCAG has not been yet explored.

Player modelling is an important part of designing serious games that best respond to user needs, as it can significantly improve both a game's effectiveness and player engagement. Past research revealed that such a user-centred approach can improve gameplay experiences (Charles and Black, 2004; Sykes and Federoff, 2006). In addition, past work revealed that video games in general have the potential to increase adoption of new programs (Lu et al., 2012), which is in line with the envisioned potential of this work. Identifying player preferences and how those could be applied to serious games is key in this effort. The use of a type-based preference model (Myers and McCaulley, 1985) to define a player as one type has been shown to be an effective approach to player modelling and has been adopted by several authors since then towards the definition of player user types. We draw upon work in the above areas to form player types that are representative of designers. 
Accordingly, in this paper we present GATE - our serious game implemented with an aim to improve designers' engagement with, and ultimately, raise awareness of the WCAG in a fun and interactive manner. We next discuss how GATE is designed based on player models which was achieved through an online survey with designers. Player user types are then created that are mapped to game design elements corresponding to each WCAG principle in accordance to the results of our survey. The game is next evaluated with designers through a mixed-methods user study. Implications and contributions are finally discussed.

\section{Related work}

In this section, the WCAG, previous work on web accessibility and tools, and serious games for increasing engagement and raising awareness are presented.

\subsection{Overview of the WCAG 2.0}

The WCAG 2.0 and the typical conformance levels that we based this work on are presented in this section. Various web accessibility guidelines are currently available, but in this paper, we focus on WCAG 2.0, which is one of the most well-established and most widely used guidelines. WCAG 2.0 involves four principles, which consist of 12 guidelines. The 12 guidelines provide the basic goals that designers should work toward (see section 4.3). Specifically, the "Perceivable" principle states that information and user interface components must be presentable to users in ways they can perceive. The "Operable" principle states that user interface components and navigation must be operable. Similarly, "Understandable" is concerned with adhering to information and states that the operation of a user interface must be understandable. Finally, "Robust" states that content must be robust enough that it can be interpreted reliably by a wide variety of current and future user agents (e.g. web browsers, media players, etc.), including assistive technologies. When assessing web designs for compliance with accessibility standards, the World Wide Web Consortium (W3C) recommends that a design could be classified as "Level A", "Level AA" or "Level AAA," with Level A representing the minimum level of conformance. Past research identified that the lack of familiarity, and in some cases, the lack of technical knowledge was one of the major challenges in engaging and adapting such guidelines (Scott et al., 2015). Our serious game is designed upon 
this premise and aims to help designers engage with the above through a gamebased informative environment.

Specific techniques and success criteria are available to designers and evaluators to determine the level of conformance in the form of code examples, resources and tests. Typically, content authors are required to understand the success criteria and then utilise techniques in order to determine conformance of a web design to those criteria. However, a common problem is that this practice has been shown to be complex and ambiguous (CEUD, 2013), which often has direct implications to the motivation to use them. In GATE, success criteria and techniques are integrated in an interactive game environment. It is anticipated that our serious game can improve on the above issues.

\subsection{Web accessibility evaluation tools}

This section identifies various automated tools and techniques that designers often use to evaluate a design for accessibility conformance. A range of inclusive design practices have been used by practitioners to help designers evaluate designs for their conformity to accessibility standards, as well as their accessibility to people living with a disability. Specifically, a platform was proposed for automatically assessing a design for its accessibility across five application areas - automotive, smart living spaces, workplace design, infotainment, and personal healthcare and wellbeing with positive results (Scott et al., 2015; Spyridonis et al., 2014). Similarly, Hersh (2017) presented an evaluation framework with an aim to assess ICT-based learning technologies for people living with a disability. From the point of view of mobile design, Mi et al. (2014) provided heuristics for evaluating the accessibility of smartphone interface designs. In an effort to empathize and understand the needs of a particular audience, Cooper (1999) was first to propose the use of personas i.e. the creation of fictional characters to represent user groups for people with disabilities. Along those lines, Kelle et al. (2015) presented how personas could be used within a Massive Open Online Course (MOOC) for learning about accessibility design. In addition, W3C recommends a number of tools and solutions that have been developed to help designers evaluate their designs for accessibility (Chisholm and Kasday, 2005). More recently, a number of simulation-based solutions have been proposed. IBM have proposed the use of "aDesigner" (IBM Research, n.d.) as a tool to aid designers assess if their web pages are accessible by the visually impaired. A 
vision and hearing simulator was developed by the University of Cambridge within their "Inclusive Design Toolkit" (2017).

While evidence from the literature suggests that accessibility design is an active area of research and practice, research has also indicated that accessibility of web designs appears to not be a primary concern amongst designers (Lazar et al., 2004). The situation has not significantly improved since then. A recent survey of Web accessibility practitioners (WebAIM, 2018) identified that lack of knowledge and awareness of web accessibility are the most important reasons why websites are still not designed to be accessible, and poor understandability of WCAG appears to be the most important contributing factor for not engaging with guidelines. Most work on accessibility design has focused on providing tools and methods such as the above that incorporate those guidelines. There is little previous research on improving the complex and laborious task of understanding such guidelines and addressing engagement issues that designers currently seem to be faced with. GATE builds upon this challenge by proposing an approach to better raise awareness and engage designers in using the WCAG.

\subsection{Serious games for increasing engagement and raising awareness}

The use of gaming techniques and technologies has had a wide variety of applications with increasing popularity. One of those is serious games (Abt, 1987; Crookall, 2010) which are increasingly applied in more areas and disciplines, as well as becoming more complex. Serious games offer interactivity coupled with immersive experiences in order to engage people in tasks and activities that are not necessarily considered fun. Their application in education and training market has ever been growing over the past decade (Meijer et al., 2018; Michael and Chen, 2005; Papaioannou et al., 2018; Susi et al., 2007).

\subsubsection{Increasing Engagement}

Recent research on serious games has expanded into areas such as healthcare and rehabilitation (Cargnin et al., 2015; Meijer et al., 2018), environment (Aubert et al., 2018), military (DeFalco et al., 2018; McGregor et al., 2016), education and training (Katsaounidou et al., 2019; Lamb et al., 2018), and decision making (Daylamani-Zad et al., 2018, 2016; Flood et al., 2018). Research has also demonstrated many examples of serious games being used for increasing engagement. The use of 
serious games has not only increased (Paraskevopoulos et al., 2014), but also optimized engagement in rehabilitation (Cargnin et al., 2015). There are many studies into the positive impact of serious games on engagement in training and education (Connolly et al., 2012; Papaioannou et al., 2018; Pourabdollahian et al., 2012). The investigation of the benefits of serious games in engaging people in a work environment is also not new. Research by Pavlus (2010) has shown that game design elements such as leader boards and feedback mechanisms help people feel more ownership and more engaged when carrying out tasks. Past work demonstrated that engagement was indeed improved when game design elements were introduced in work-related activities (Shneiderman, 2004). Halan et al. (2010) found that the use of game mechanics helped increase participation in an online training by $61 \%$. In order to maximize engagement, the Self-Determination Theory (SDT) (Deci et al., 1999) has been used to understand user motivation in carrying out tasks. SDT discusses that human beings can be intrinsically (based on wants and needs) or extrinsically (based on rewards) motivated when carrying out a task. Research has shown that intrinsic motivation is the most effective, as it is supported by three core psychological needs - competence, autonomy, and relatedness, which when fulfilled help users feel more motivated (Deterding, 2015). Fundamental work by Ryan et al (2006) investigated the application of SDT in video games and found that it is associated with enjoyment and players' sense of immersion in gameplay. More relevant to this work, Stiegler and Zimmermann $(2015,2014)$ explored the use of gamified systems in engaging developers through an online platform and proposed a set of gamification patterns. The above platform was primarily designed to connect developers in building accessible applications, but not to address issues with the WCAG. Similarly, Grammenos (2008) provided developers a first-hand experience of an inaccessible game with an aim to educate them about the importance of game accessibility guidelines.

\subsubsection{Raising Awareness}

The body of research also indicates that serious games have been successfully used for raising awareness. Recent research demonstrates an increasing awareness in regards to communal policing in the public through the use of serious games (Sorace et al., 2018). Others demonstrate results in raising awareness on genetic literacy (Oliveri et al., 2018), antimicrobial resistance (Molnar, 2019) and stress awareness 
(Holz et al., 2018) through serious games. In engineering, serious games have been used to raise awareness on agile methodologies and portfolio management (Stettina et al., 2018) and software security (Pandit et al., 2018; Yasin et al., 2018). Cultural awareness and historical heritage have also benefitted from serious games (Katerine Marceles and Burbano, 2018).

\subsubsection{The need for a Serious Game}

According to the body of research, serious games pose as a successful mean for engaging individuals with activities around the topic at hand. However, and despite their popularity, in current serious games literature web accessibility is scarcely addressed. Additionally, it has been suggested that "accessibility is solved at the design phase" (Lambert, 2018). Accordingly, GATE makes use of an interactive game environment where designers can engage with the WCAG guidelines prior to any development and during the design phase.

Work by Daylamani-Zad et al. (2014) identified that there is a limit to how close a task in such game environments should be to the real-world scenario. Building upon the Lusory and Ludic dimensions of serious games (Aleven et al., 2010; Suits, 2005), which explain that if Lusory concepts (the goal of the game and the efficient means to achieve it) and Ludic concepts (mechanics, story, aesthetics, and technology) are too far apart, then the game will loose its efficiency, whilst if they are too close, then the game is in danger of becoming boring. A balance has to therefore be reached between these concepts. Accordingly, a greater abstraction level between the realworld scenario and the game scenario in GATE would increase the enjoyment level, yet it would also potentially increase the difficulty for achieving the original goal of the training. Alternatively, the closer the real-world and the game-world are, the easier it would be to achieve the training goal, but this comes at the cost of user enjoyment and therefore engagement. The above is also taken into consideration in the design of GATE.

\subsection{Player modelling in serious games}

Player modelling and its importance to serious games is discussed next. Player modelling is often utilised in games to ensure that they would address the needs and preferences of their target audience. Karpinskyj et al. (2014) have identified gameplay preferences, playing style or skill level as important elements of player 
modelling. The work by Orji et al. (2013) that builds upon the BrainHex model is an example of player modelling based on playing style. Previous research focused on player modelling via player types. For example, Göbel et al. (2010) deployed a variation of Bartle's model where a quadruple of normalised values indicates how much the player fits into the killer, achiever, socializer, and explorer player types, and is updated as the player makes decisions. Similarly, Cowley et al. (2013) present a real-time classifier of player type for the Demographic Game Design (DGD) player typology (conqueror, manager, wanderer, and participant), with approximately $70 \%$ accuracy. Marczewski developed the Gamification User Types HEXAD framework and suggested different game design elements that may support different user types (2015). The importance of tailoring games to users' personalities was also highlighted in previous work. Ferro et al. (2013) have sought to improve the design of games by deriving relationships between player types, personality types and traits, and game elements and game mechanics, resulting in five category groupings: dominant, objectivist, humanist, inquisitive, and creative. Player modelling is therefore central to the design of GATE.

\subsection{Research aim and approach}

Research revealed that the WCAG guidelines are complex to learn and this often demotivates designers from using them in their practice. Numerous tools and methods exist to address this issue, but those incorporate those guidelines for automatic assessment of designs, which may be subject to error, and after development has taken place. There is no previous work that focused on helping improve designers' engagement with WCAG. The use of serious games was shown to be effective in helping users engage and train in numerous settings. Accordingly, in this paper, we aim to address the above by proposing a serious game that promotes the WCAG guidelines in an effort to improve engagement with the available web accessibility guidelines, and ultimately, to raise awareness about WCAG. GATE was implemented following a multi-layered approach whereby the design was informed and tailored to user needs and preferences in Study 1, and it was then evaluated by users in Study 2. Figure 1 presents this approach. 


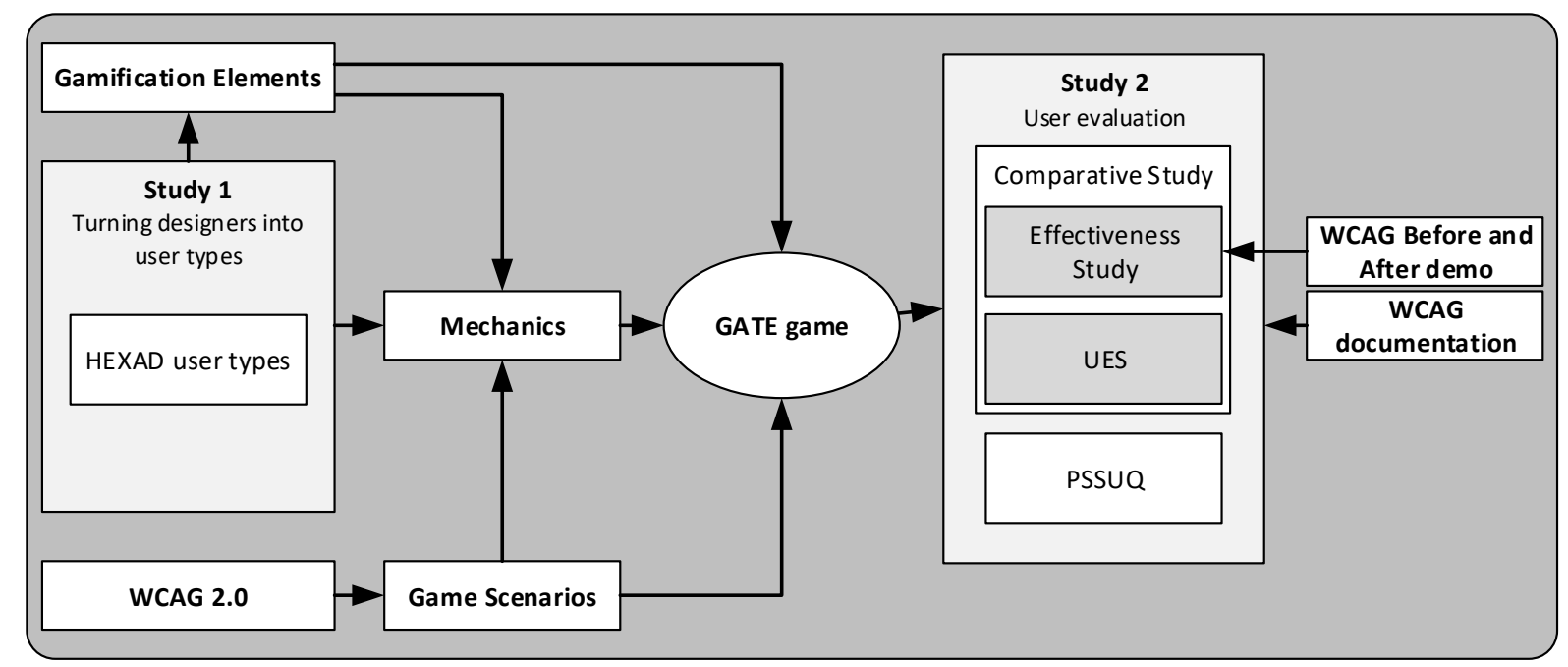

Figure 1. Summary of approach for development and evaluation of GATE

\section{Study 1 - Turning designers into user types}

The serious game was informed by a user study through an online survey with designers with an eye on tailoring the game to potential users' preferences based on empirical data.

\subsection{Study 1 procedure and materials}

In this work, player modelling was implemented by adopting the Gamification User Types HEXAD framework using the approach put forward by Tondello et al. (2016) in order to identify player types for GATE, as it explicitly utilises the SDT. HEXAD proposes six user types that can be used to screen a target audience and choose adequate game design elements for each user:

i. Achiever (intrinsic type). Motivated by challenges, completion of tasks and progression.

ii. Free Spirit (intrinsic type). Looking to explore or create.

iii. Philanthropist (intrinsic type). Motivated by a sense of altruism.

iv. Socialiser (intrinsic type). Looking to create social connections and a sense of being part of a group.

v. Player (extrinsic type). Motivated by extrinsic rewards.

vi. Disruptor (none of the above). This type is a group rather than a single type. It is looking to disrupt the system by influencing the system or others.

The HEXAD survey instrument was therefore used to identify user types that are appropriate for our target audience. The survey contained sections about 
demographics (age, gender, education, and awareness of accessibility guidelines), and the 30 User Types survey items outlined in Tondello et al. (2016). Participants (see section 3.2) were asked to rate those items on a 7-point Likert scale ('Strongly disagree' to 'Strongly agree'). Responses were collated, and a score-per-type was calculated for each participant. Specifically, in order to evaluate how representative each user type is for a participant, the user type scores for all items relating to a type were added up with the maximum score per type being 35 (100\%) (Tondello et al., 2016). Mean scores and Standard Deviations (SD) were further produced to summarise the findings (Table 1). The average distribution of user types in participants was also calculated and presented in Figure 2. As illustrated in Equation 1, if $H E X A D$ is the set of all user types, then $r_{h, p_{i}} \in R_{p_{i}}$ represents the score rated by participant $p_{i}$ for each $h \in H E X A D$. The calculation of Mean and SD is demonstrated in the equation below.

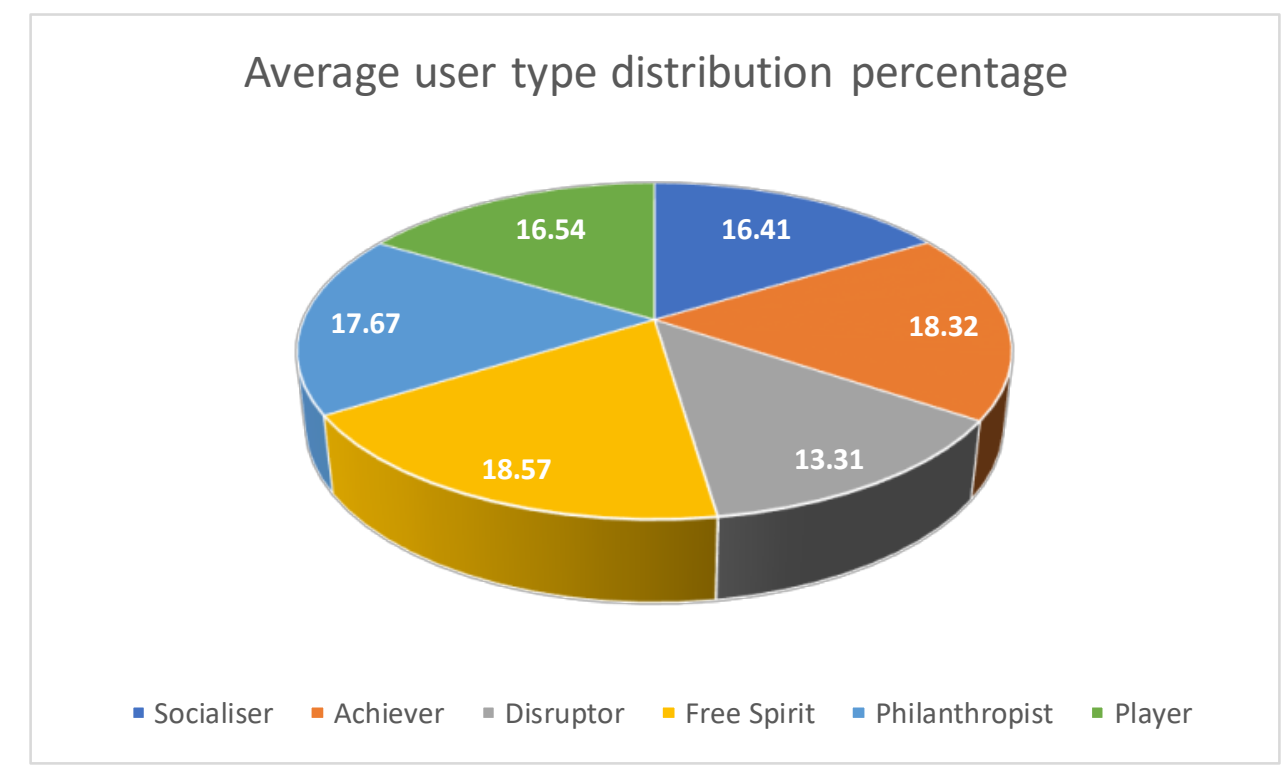

Figure 2. Average distribution percentage of user types in participants. The diagram illustrates a high identification with all user types in the participants.

$$
\begin{gathered}
\text { HEXAD }=\begin{array}{c}
\{\text { Socialiser, Achiever, Disruptor, Free Spirit, Philanthropist, Player }\} \\
R_{p_{i}}=\left\{r_{h} \mid h \in H E X A D\right\}: p_{i} \in \text { Participants } \\
\text { Mean }(h)=\frac{\sum R_{h, p_{i}}}{\mid \text { Participants } \mid}: p_{i} \in \text { Participants } \& h \in H E X A D \\
S D(h)=\sigma\left(R_{h, p_{i}}\right): p_{i} \in \text { Participants } \& h \in H E X A D
\end{array}
\end{gathered}
$$

Equation 1. Calculating the Mean and Standard Deviations for each HEXAD user type. 
Additionally, we define 'main user type' as the type in which the participant achieved the highest score among the six user types. Whilst a main user type allows us to identify dominant preferences, participants exhibited traits and preferences that relate to all six user types (Figure 2). Therefore, all six user types need to be considered in the design of the system that accommodates for the designer population. The identification of a main user type thus allows us to determine the distribution of user types in order to prioritise in facilitating for each user type. Accordingly, the distribution of participants' main user type was averaged (Table 1) and then used to inform GATE's game design elements. Equation 2 illustrates the calculation process for the main user type distribution.

$$
\begin{gathered}
\text { MainUserTypes } \left.^{\text {MainUSerType }} p_{p_{i}}=\max \left(r_{h, p_{i}}\right) \mid r_{h, p_{i}} \in R_{p_{i}} \& h \in H E X A D\right\} \\
\text { Distribution }_{h}=\%\left(\frac{\sum \mid \text { MainUserType } p_{p_{i}}=h \mid}{\mid \text { Participants } \mid}\right): p_{i} \in \text { Participants \& } h \in H E X A D
\end{gathered}
$$

Equation 2. Identifying main user type for participants and calculating the distribution.

\subsection{Study 1 participants}

Thirty-one (14 female; 17 male) designers were recruited to take part in this survey via online postings in relevant communities and through related professional networks. The participants were aged between 18-37 years old (Mean=26.53; $\mathrm{SD}=4.94)$ and more than half $(53.4 \%)$ had never used WCAG before, which is consistent with past research about designers lacking required technical knowledge in practice.

\subsection{Designer user types mapped to game design elements}

The results of our online survey are presented and further mapped to game design elements in this section.

Table 1 presents the Mean score, SD and Distribution for the six user types according to the results of our survey. All user types were considered in the design of GATE. Specifically, the findings reveal that the "Free Spirit" and the "Achiever" are the top two representative types to the participants based on their Mean score. These data suggest that intrinsic motivation is most important to the targeted audience and it will be mostly utilised in GATE. However, it has to be noted that 
"Player" also scored high both in its Mean and Distribution suggesting that extrinsic motivation should also be considered in GATE, as most players initially come into a system due to rewards. On the other hand, "Disruptor" was not as commonly identified as a main user type. It did not scored high by any of the participants as a main user type ( $0 \%$ distribution), but nevertheless, the findings suggest that it makes up a smaller portion of the participants' preferences $(M=19.66)$ and as illustrated in Figure 2, "Disruptor" represents $13.31 \%$ of the participants' preferences which is clearly impactful. Hence, it will be accordingly considered in GATE. The GATE game mechanics were then tailored in accordance to the characteristics of each of the identified user types for the targeted audience, outlined in

Table 1.

Table 1. GATE User Types

\begin{tabular}{llll} 
User Type & Mean & SD & Distribution (\%) \\
\hline Free Spirit & 27.43 & 4.65 & 29.03 \\
Achiever & 27.06 & 4.03 & 32.26 \\
Philanthropist & 26.10 & 3.32 & 6.45 \\
Player & 24.43 & 6.23 & 22.58 \\
Socializer & 24.23 & 5.50 & 9.68 \\
Disruptor & 19.66 & 5.12 & 0
\end{tabular}

The design goal of GATE is to improve engagement with WCAG. Accordingly, we designed GATE based on game design elements proposed by Marczweski (2015) for each user type in order of their Mean score (highest to lowest). Previous research by (Brondi et al., 2015) highlighted the importance of challenges in engagement. On this premise, we further map those design elements to the WCAG guidelines through relevant challenges and tasks, and based on the framework proposed by Spyridonis et al. (2017) with an eye on increasing engagement. Section 4 discusses the final mapping for GATE.

\section{GATE design and implementation}

The game's design and implementation decisions that utilise our Study 1 findings are presented next. The game was designed based on two dimensions of requirements: 1. Mechanics proposed by HEXAD that cater for the identified user types, and 2. 
Scenarios that would enable implementation of the WCAG and the identified mechanics in (1). As stated previously, all participants (designers) identified with every user type in varying extents (Figure 2), therefore, by utilising (1) and (2) we can ensure that all designers can engage with every WCAG guideline included in GATE. The theme used was a contemporary setting, but with a futuristic touch to ensure that there is a greater abstraction level between the real-world scenario and the game scenario so that enjoyment is increased in line with the findings by Daylamani-Zad et al. (2014). The summary of design and implementation architecture is presented in Figure 3 . The design and implementation is explained in detail in this section.

The serious game was implemented with Unity and C\#. The use of this engine allows for future releases on suitable mobile platforms, such as tablets and smartphones. The current version was ported as a desktop PC game and as a webbased game that is playable in a browser. GATE uses a secure NoSQL database to store user data, user progress, and achievement and certification capabilities.

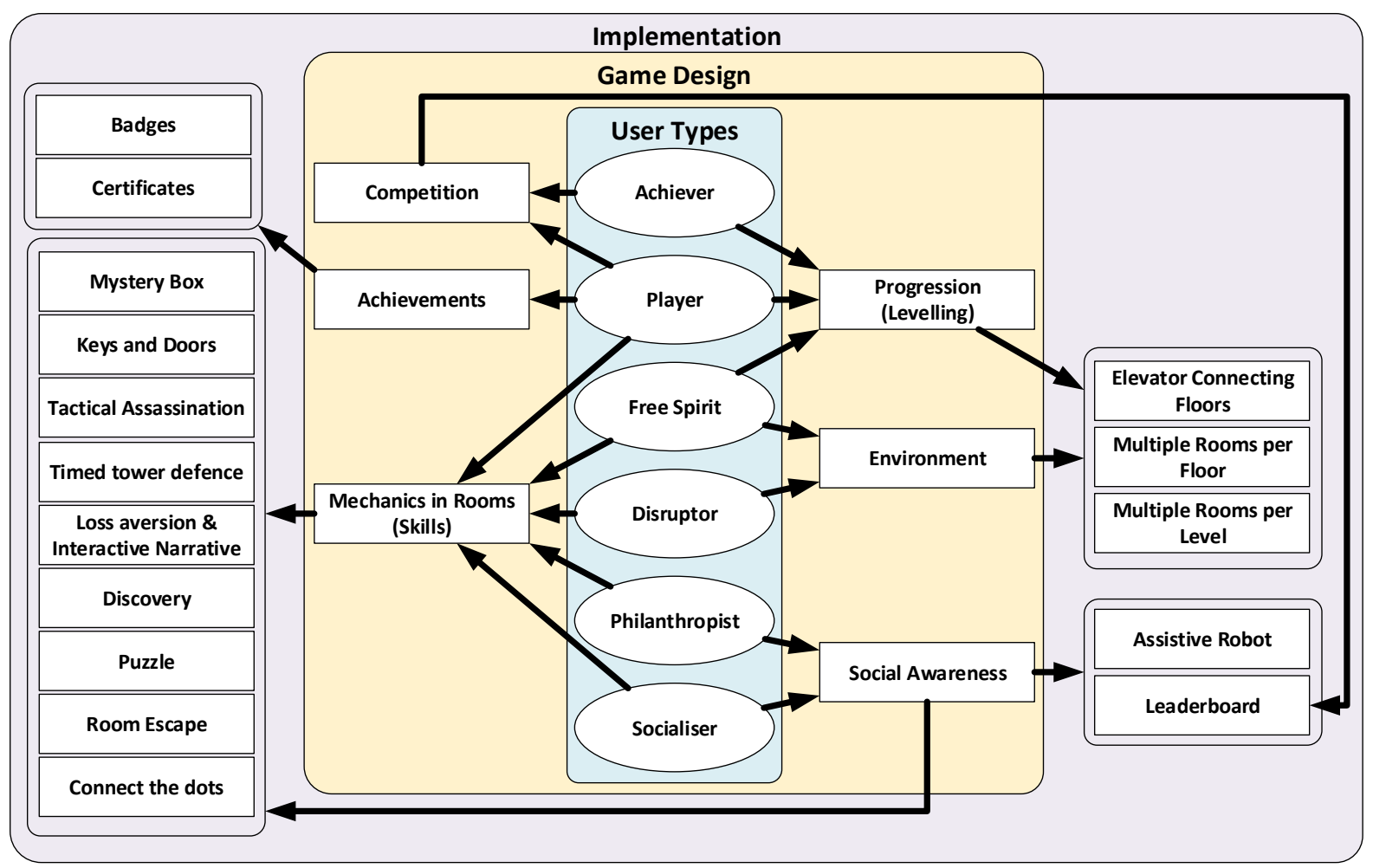

Figure 3. Design and implementation of GATE game, illustrating the relations between various components and mechanics.

\subsection{Game structure and mechanics}


The game's overall structure and how it incorporates the WCAG and user types is now discussed. The location used in GATE is an office building to match the player's perception with the reality of working as a designer in a company. The office building has multiple rooms spread across four floors which are connected via an elevator (Figure 4). Each floor represents a 'Principle' of the WCAG and would encompass rooms that act as level settings, which are dedicated to a specific 'Guideline' from the WCAG. The incorporation of levels supports the Achiever user type through progression mechanics. Figure 5 illustrates the hallway for a typical floor with rooms that the user can choose to enter and explore.

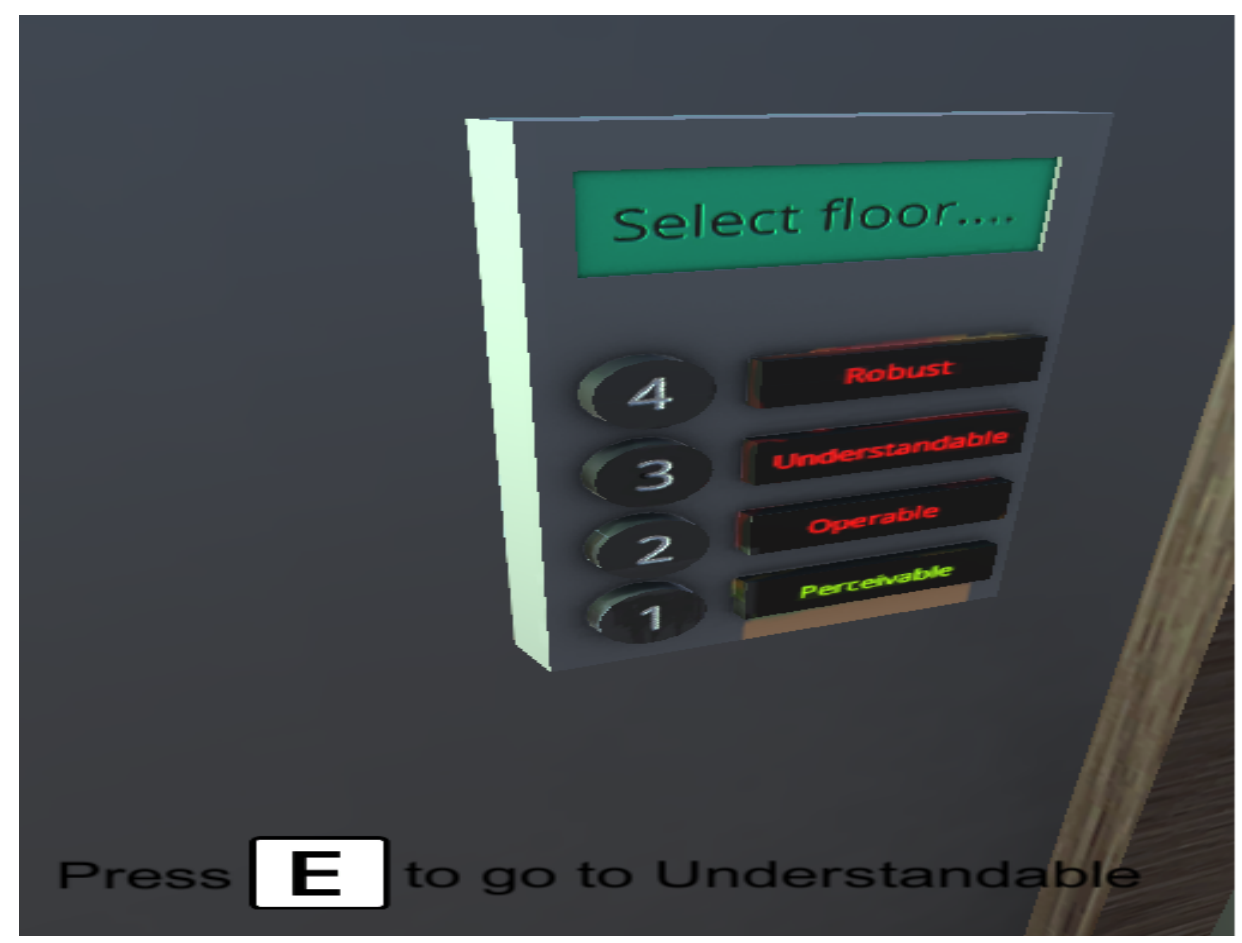

Figure 4. Elevator tracking player progress and connecting various floors.

Each room holds a new challenge for the player. Challenges are also mechanics that are in support of the Achiever user type. The player is free to explore the various floors and rooms in any order they wish to, and therefore, incorporating exploratory mechanics and providing a nonlinear gameplay, which are both mechanics that support the Free spirit user type. Upon overcoming the challenges in each room, the player would receive an achievement badge for the corresponding guideline (Figure $6)$, supporting the Player user type. Once the player has overcome the challenge, they are provided with a briefing about the specific guideline they have been addressing with links back to the guideline for more in-depth information about 
success criteria. This is in line with the Achiever user type who are looking to learn new skills and improve themselves. Once a room challenge is addressed, the next challenge for the room is unlocked. For example, once the player overcomes a guideline challenge at Level $A$, the challenge at Level $A A$ is unlocked. This mechanic supports both Progression for Achievers and Unlockable content for the Free Spirit user types.

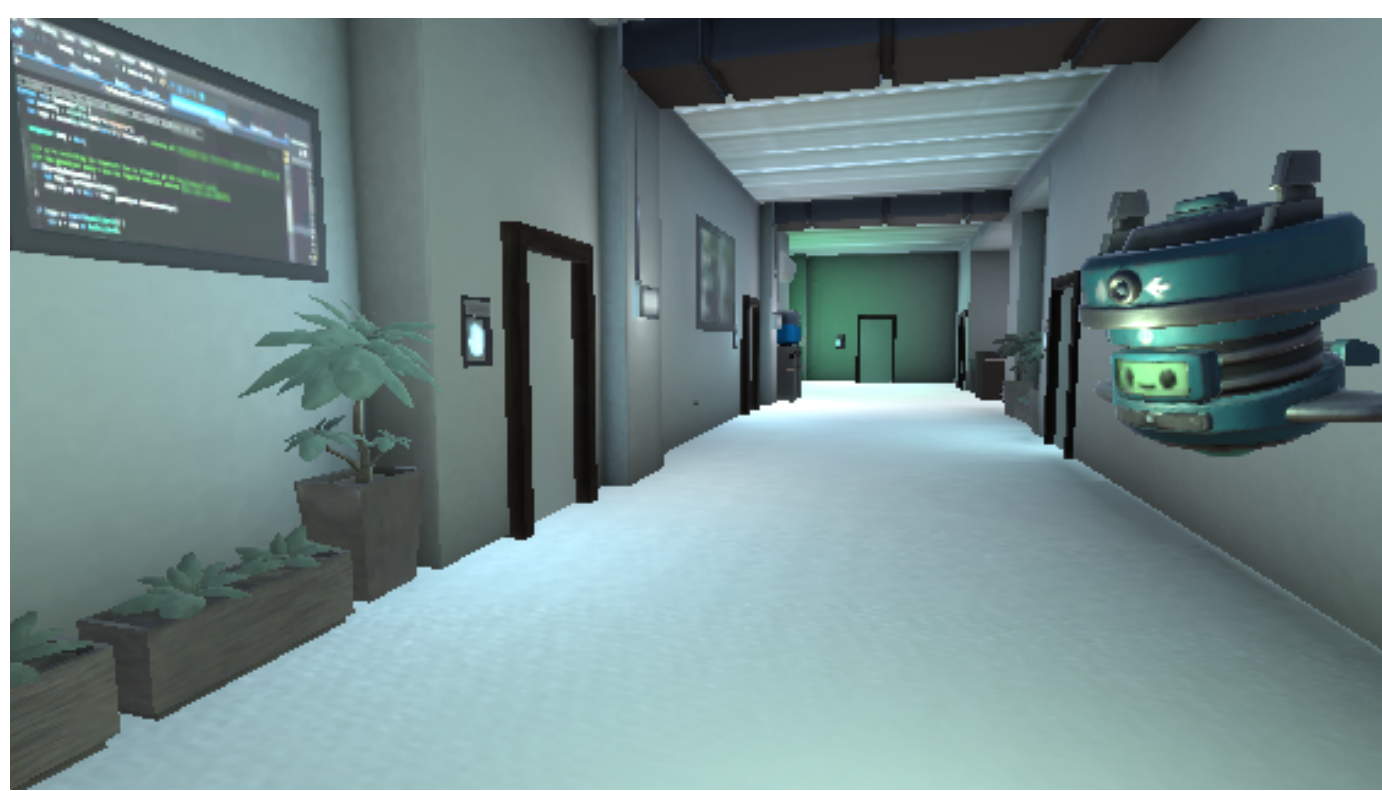

Figure 5. A typical hallway of a floor where doors would lead to rooms with various scenarios.

The elevator connecting the floors also has controls and indicators for each floor and room, which will light up once a challenge has been completed. This allows the user to monitor their progress in support of the Achiever user type. Once all the levels for a 'Principle' are completed, the player is issued a certificate indicating its completion at the corresponding level (A, AA, AAA), also in support of the Achiever user type. Players may join the game at any floor they wish, supporting the need for autonomy to achieve intrinsic motivation in GATE. This also supports in transitioning Disruptor user types into more engaged user types through incorporating an Anarchic gameplay. As Disruptors can freely roam around and explore without engaging with the gameplay, intrinsic motivation elements would help engage them with the game through their anarchic style and gradually transition to another user type. This game structure should allow players to learn about the guidelines through different challenges and understand the importance of classification and success criteria of designs. 


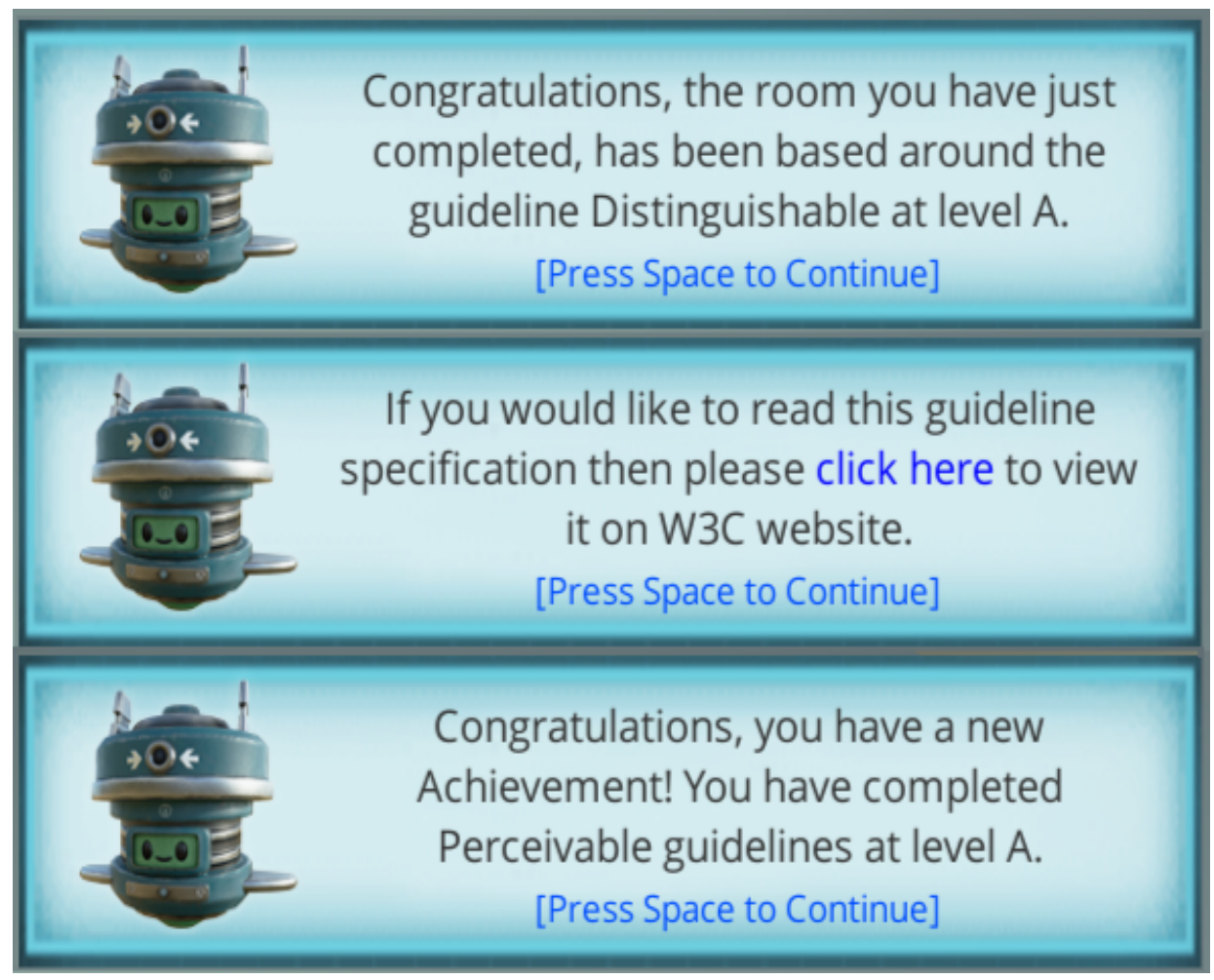

Figure 6. Achievement messages corresponding to guidelines.

\subsection{Assistive technologies and social interactions in GATE}

The importance of assistive technologies for GATE is demonstrated in this section by mapping the identified user types to social mechanics implemented through a companion robot. This robot has been designed into the game and accompanies the player throughout. The robot is designed as a metaphor for Assistive Technologies and is therefore called 'Assistive Robot' (see Figure 4, top-right). The robot communicates with players and either helps/guides their progress or needs their help at various challenges. This enables the implementation of Knowledge sharing mechanics for the Philanthropist user type, as well as creates a social awareness and sense of belonging for players in support of the Socializer user type. Throughout the game, the Assistive Robot requires players to collect and spend items and collectables; for example, the items discovered in one scenario can be used in another (see next section for GATE's scenarios). This mechanic supports the Philanthropist user type.

We also included a leader board social mechanic in the game, as it allows for a sense of belonging and ownership (Pavlus, 2010), while supporting a competitive experience. Specifically, leader boards allow for supporting social comparison, social competition and social discovery in line with the Achiever, Socializer and Player user 
types. Additionally, leader boards help to overcome feelings of loneliness that might arise in gamified experiences. The leader board in GATE helps to enable competence amongst players, creating in that way incentives for better performance, as well as for mastering the environment and outcome. The above is in line with the relatedness and competence needs of SDT to achieve intrinsic motivation in GATE.

\subsection{WCAG principles mapped to game scenarios}

We utilise different scenarios in each level so that the player feels both challenged and motivated to discover new mechanics, whilst engaging with the WCAG.

Accordingly, the GATE scenarios implement the WCAG principles and identified game mechanics as described below.

\section{Principle 1 - Perceivable}

The Perceivable principle is presented on the first floor. This principle consists of four guidelines which have been mapped to specific game scenarios.

- Guideline 1.1 - Text Alternatives (provide text alternatives for non-text content): We implemented a Mystery Box scenario where the player enters a dimly lit room and finds a box at its centre. The player tries to open the box, but the item inside is unclear. The Assistive Robot will explain what it can scan, and the player is presented with an HTML code box and must write the description in the ALT tag of an image. If the player enters a correct description, the item will appear clearly and can be collected. This level includes exploratory tasks, a challenge, and a reward and collection, which address the Achiever, Free spirit and Player user types. Figure 7 illustrates the stages of this scenario.

- Guideline 1.2 - Time-based Media (provide alternatives for time-based media): The Mystery Box scenario is similarly implemented for this level, where a blurred video is being used in a noisy room. The Assistive Robot will communicate with text and the player needs to fill the ALT tag to make the video clear and receive the video's message which is the password to unlock the door and finish the level. This level incorporates mechanics from categories of challenges, unlockable content, knowledge sharing and rewards which address the Achiever, Free spirit, Philanthropist and Player user types. 


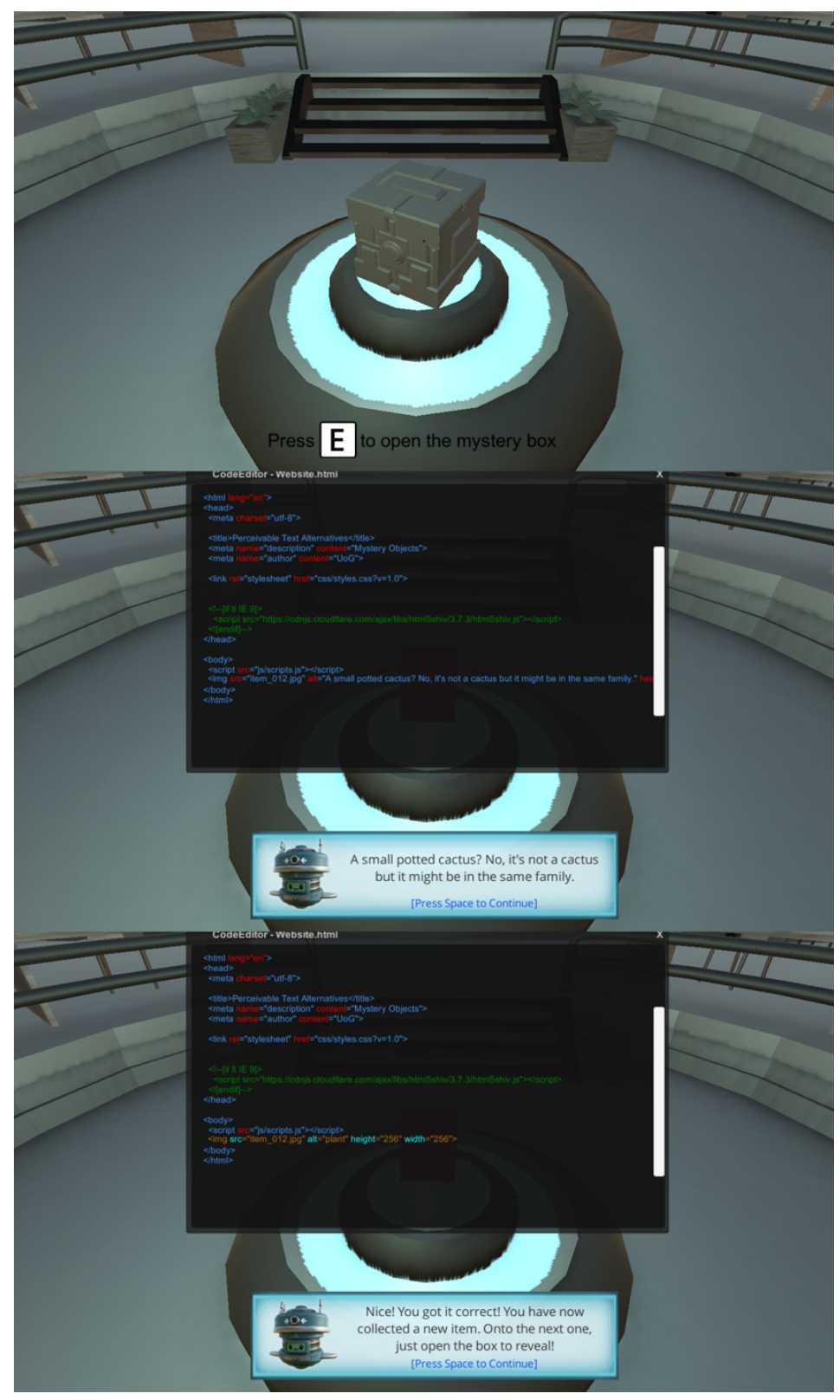

Figure 7. Mystery box for the Text Alternatives scenario (Top), HTML code box and the alt tag clue (Middle), correctly filled alt tag with a collection message (Bottom).

- Guideline 1.3 - Adaptable (create content that can be presented in different ways): The corresponding scenario is based on Keys and Doors, where Keys are content such as text, pictures, videos, etc. and Doors are a phone/PC platform, etc. Players should fit the content into the platform provided. If the platform is out of reach, then the player would access it with the help of the Assistive Robot. The collectables from scenarios such as the Text Alternative can be used at this level as content, if the user has collected them. This scenario includes exploratory 
tasks, a challenge and collection, and social discovery which address the Achiever, Free spirit and Socialiser user types.

- Guideline 1.4 - Distinguishable (make it easier for users to see and hear content): Tactical Assassination is the scenario mapped to this guideline. The player needs to find a specific target in the crowd. Everyone is the same colour; hence, the Assistive Robot will help to apply filters to make the target visible. This scenario includes exploratory tasks, unlockable content, a challenge, a quest, team activity, and rewards in line with the Achiever, Free spirit, Socialiser and Player types.

\section{Principle 2 - Operable}

This principle consists of four guidelines and is located at the second floor of the building.

- Guideline 2.1 - Keyboard Accessible (all functionality available from a keyboard): This guideline is mapped to a Discovery and Coordinated Action scenario, where the player would need to fix a keyboard in order to type in a password by finding the missing keys. The Assistive Robot suggests shortcuts. There are nokeyboard zones and no-mouse zones, which the player would need to overcome. This scenario includes exploratory tasks, unlockable content, a challenge, a quest, team activity, and rewards in support of the Achiever, Free spirit, Socializer and Player user types.

- Guideline 2.2 - Enough Time (provide enough time to read and use content): This has been mapped to a Timed Tower Defence scenario. The player has to destroy 100 enemies in the time given. Players cannot win until the Assistive Robot helps them increase the time limit. This scenario has an epic challenge, gifting, team activity and creativity tools mechanics, which support the Achiever, Free spirit, Philanthropist, Socializer and Player.

- Guideline 2.3 - Seizures and Physical reactions (do not design content that may cause seizures and physical reactions): To help the players realise the possible features that could cause seizures, a combination of Loss Aversion and Interactive Narrative is used. At the start of the level, the Assistive Robot breaks down because of multiple flashing points, and through conversation, the player turns them off, and reduces the area they affect. Finally, the player makes a shield for the robot to ensure this does not happen in any other room. From here 
onwards, the player needs to recharge the shield at intervals to remind them of the seizure issues. This scenario includes an exploratory task, gifting, rewards and social discovery which address the Free spirit, Achiever, Player, Philanthropist and Socializer user types.

- Guideline 2.4 - Navigable (provide ways to help navigate, find content and determine position): This guideline is suitably mapped to a Discovery scenario. The level starts with the player faced with many rooms and corridors. The player needs to finish a task of downloading and a task of uploading a file in order to progress. The Assistive Robot suggests using the map and prompts the player to find the home page, check the page title and check for any breadcrumbs to go back to where they were after accomplishing the task. This level includes exploratory tasks, nonlinear gameplay, unlockable content, quests, knowledge sharing and rewards which support the Free spirit, Achiever, Player, Philanthropist and Socializer types.

\section{Principle 3 - Understandable}

This principle consists of three core guidelines and is located on the third floor.

- Guideline 3.1 - Readable (Make text content readable and understandable): This guideline has been mapped to a selection of Puzzles where the level would take the default language of the game and use a different language to show the instructions. The player is prompted with an HTML code block and needs to find the 'http header' and change it back to their own language. This level includes quests and rewards, which address the Achiever and Player user types.

- Guideline 3.2 - Predictable (Make Web pages appear and operate in predictable ways): The guideline is mapped to a Room Escape scenario. The player would start in a locked room, and there is a panel next to the exit door. The player can prompt the HTML code with the help of the Assistive Robot, but s/he needs to find the passcode first; the Input field is locked, so the player needs to create an 'on focus' for the input in order to enter the passcode. Finally, the player must create a submit button with a 'select tag' to submit the passcode. This level involves unlockable content, learning new skills, a challenge, team work and rewards which support the Achiever, Free spirit, Socializer and Player user types.

- Guideline 3.3 - Input Assistance (Help users avoid and correct mistakes): A Connect the Dots scenario is mapped to this guideline where the player needs to 
access the HTML code panel with the help of the Assistive Robot and connect validation and labels to fields in order to enter the information needed to complete the level. This level includes unlockable content, a challenge, rewards and team play, which address the Achiever, Free spirit, Socializer and Player user types.

\section{Principle 4 - Robust}

This principle consists of one core guideline and is located at the top floor. It has to be noted that even though each floor has different number of active rooms, there is always a similar number of room doors available in the corridor and the player would need to find active doors that allow them to enter rooms.

- Guideline 4.1 - Compatible (Maximise compatibility with current and future user agents, incl. assistive technologies): This guideline has been mapped to a Connect the Circuit scenario where the player is faced with a locked electronic door. The circuit that runs the power to the door is broken and the player would need to fix this. The Assistive Robot is unable to read the page, so it informs the player that the information is incompatible. The player would need to fix IDs, closing and opening tags to make sure the current can run through to the door so that the Assistive Robot can open the door. This level includes unlockable content, a challenge, team activity and rewards which would support the Achiever, Free spirit and Player user types.

\section{Study 2 - User evaluation}

The hypothesis being tested in this research work is that GATE is as equally effective as W3C's existing online documentation for WCAG, but it is more engaging and user friendly. Accordingly, an empirical user evaluation was carried out to address two main aims:

A1. Determine whether GATE provides similar results with the existing online documentation whilst being more engaging. This was addressed through a comparative user study of GATE and the current WCAG documentation ${ }^{1}$. The standardised User Engagement Scale (UES) questionnaire (O'Brien and Toms, 2010) was then adopted to compare the user engagement levels between GATE and the above documentation, which includes questions that

\footnotetext{
${ }^{1}$ https://www.w3.org/TR/WCAG20/
} 
specifically address complexity (e.g. player confusion) and laboriousness (e.g. demanding gameplay) dimensions in line with the research problem identified in this work.

A2. Determine whether designers' preferred GATE as opposed to the online documentation and what is their perceived satisfaction with using it. The standardised Post-Study System Usability Questionnaire (PSSUQ) presented by Lewis (2002) was similarly used and adapted to fit this study in order to address this aim.

Written informed consent was obtained from all participants before starting the evaluation.

\subsection{Study 2 procedure and materials}

The user evaluation consisted of three stages; (i) a briefing stage, (ii) the comparative user study, and (iii) the PSSUQ stage (Figure 1), in accordance with the above aims. Specifically, all participants were initially briefed about the purpose and aims of the research study in the briefing stage (Stage i). This stage lasted approximately ten minutes.

The second stage (Stage ii) was then carried out with participants being divided into control group and experimental group (Campbell and Stanley, 2015) to assess (a) whether the control group ability to identify accessibility issues with the online documentation was statistically significant different from the experimental group ability with GATE, and (b) whether GATE is more engaging compared to the online documentation. Accordingly, the control group was assigned to the online documentation mentioned earlier, which is an established resource that has been produced as a summary of the WCAG. The experimental group was assigned to GATE for the similar purpose. All participants, regardless of group allocation, were asked to complete a demographics questionnaire at the beginning of the study and were told to use their allocated approach freely to familiarise themselves with their content.

Both groups were then provided with the full HTML and CSS codes of the website from W3C's Before and After demo ${ }^{2}$, an established web-based resource that shows an inaccessible version of a website, an accessibility audit report for it, and the

\footnotetext{
${ }^{2}$ https://www.w3.org/WAl/demos/bad/
} 
improved version. The demo is typically used to raise awareness on web accessibility or as a practical example for designers and developers. However, for the aims of this study, the participants were only provided with the "Before" (inaccessible) version. They were then asked to carry out the task of inspecting the 'Homepage' and the respective code against the guidelines checklist provided in Table 2, and identify and write down as many accessibility issues as possible based on their experience of using their allocated approach. The checklist was compiled based on existing accessibility issues in the provided audit report from the demo. The above task and materials were identical for both groups. Participants in the experimental group were also asked to adopt a 'think-aloud' approach, which enabled them to verbally share their thoughts while interacting with GATE (Martin and Hanington, 2012). In order to minimise interference with the process, when participants wanted to make a comment, we asked them to pause the game, and to continue it after their comment. Written notes were taken during each session by the authors. The participant responses were then analysed by comparing those to the audit report, and they received one point for each correctly identified issue for ease of analysis. There are 27 reported accessibility failures on the Homepage (27 points in total), which are presented within 10 annotated notes.

On completion of stage two, all participants from both groups were asked to complete the UES questionnaire to assess their level of engagement with each approach. The user study was carried out in a lab setting in a controlled environment using a PC. Each user test session lasted approximately 80 minutes.

In stage three (Stage iii), participants in the experimental group were lastly asked to complete the PSSUQ, which was used to gain insight into their perceived satisfaction with using GATE. This final stage lasted approximately 8 minutes.

Table 2. Accessibility audit checklist for the comparative study 


\begin{tabular}{l|l} 
Principle & Guideline \\
\hline \multirow{3}{*}{ 1. Perceivable } & 1.1 Text Alternatives \\
\cline { 2 - 2 } & 1.3 Adaptable \\
\cline { 2 - 2 } 2. Operable & 1.4 Distinguishable \\
\hline \multirow{2}{*}{ 2.1 Keyboard Accessible } \\
\cline { 2 - 2 } 3. Understandable & 3.4 Navigable \\
\cline { 2 - 2 } & 3.1 Readable \\
\cline { 2 - 2 } & 3.3 Input Assistance \\
\hline \multirow{2}{*}{ 4. Robust } & 4.1 Compatible
\end{tabular}

\subsection{Study 2 participants}

A purposive sampling approach was used for this study. Accordingly, 20 designers ( 8 female; 12 male) were recruited to participate in the user evaluation via online postings and through related professional networks. They were aged between 24-45 years old (Mean=30.5; SD=6.14). The participants were equally divided between the two study groups. All of them had previous experience of playing video games and had varying level of familiarity/expertise with accessibility design, which is summarised in Table 3.

Table 3. Participant self-declaration of level of familiarity/expertise with accessibility design

\begin{tabular}{ccccc} 
& None & Aware & Knowledgeable & Expert \\
\hline & 4 & 7 & 5 & 4 \\
\hline Total Count 20 & & & &
\end{tabular}

\subsection{Comparative User Study results}

The results of our comparative user study (Stage ii) are presented in this section in accordance to the aims presented earlier.

\subsubsection{Effectiveness results}

Overall, the participants performed similarly in identifying accessibility issues, which confirms that working with GATE can be as effective as working with the WCAG online documentation. This section presents the analysis of the results from this stage of the study. 
Figure 8 shows the box-plot of the effectiveness study for the experimental group (GATE) and the control group (WCAG documentation). The performance of the two groups was similar, which means the effectiveness of GATE and WCAG as a means for communicating the WCAG is similar.

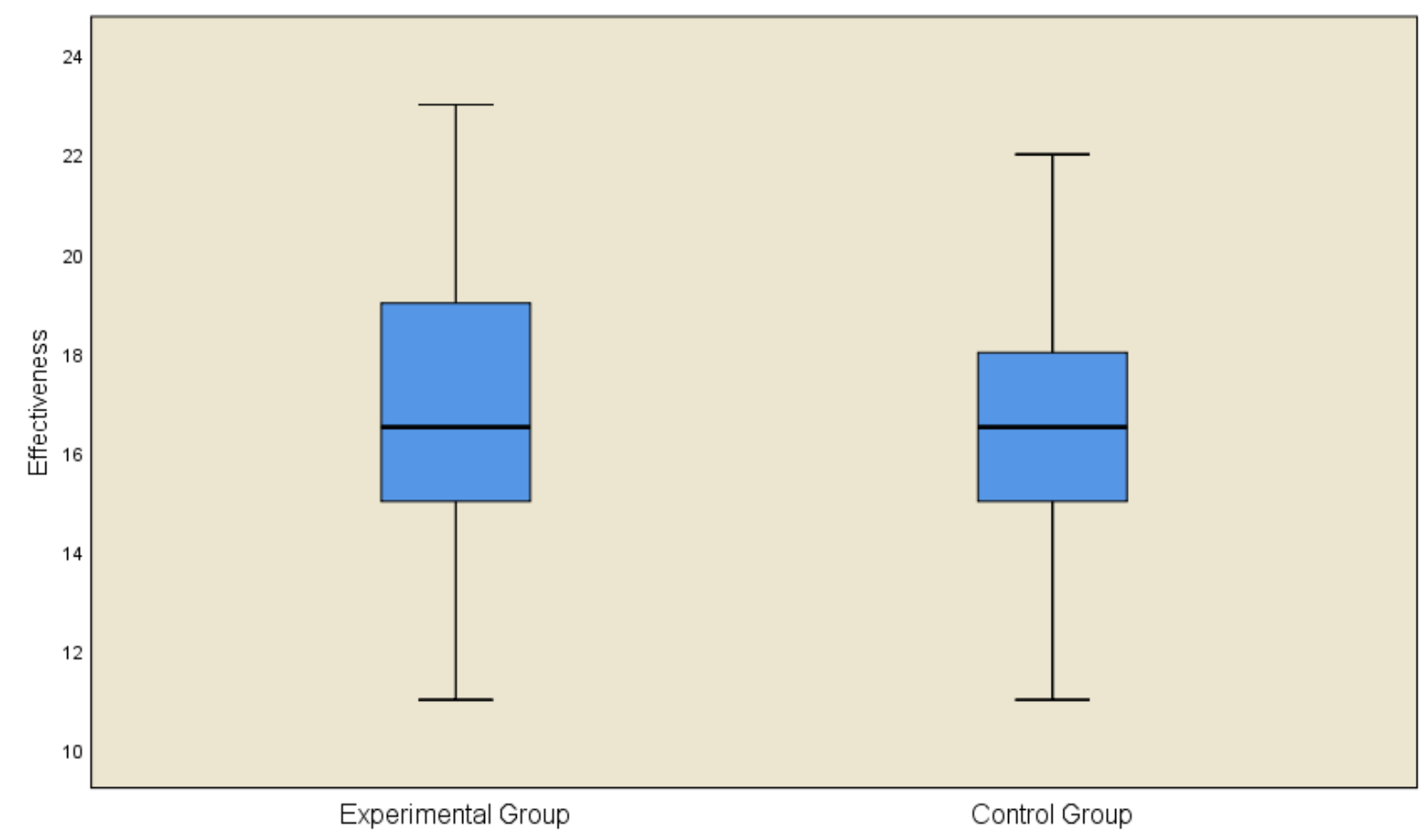

Figure 8. Box-plot for the effectiveness study in experimental group (GATE) and the control group (WCAG documentation).

Table 4 presents the descriptive data of the comparative study for both groups. As can be seen, the means for both groups are similar $(M=16.8$ for the experimental and $M=16.5$ for the control group). The best response in the experimental group is higher than the control group. Similarly, the standard deviation of the experimental group is also marginally higher than the control group.

Table 4. Descriptive data for the comparative study between the experimental group (GATE) and the control group (WCAG documentation)

\begin{tabular}{|c|c|c|c|c|c|}
\hline & $\mathbf{N}$ & Min & Max & Mean & SD \\
\hline $\begin{array}{l}\text { Experimental } \\
\text { Group }\end{array}$ & 10 & 11 & 23 & 16.8 & 3.6 \\
\hline Control Group & 10 & 11 & 22 & 16.5 & 3.32 \\
\hline
\end{tabular}


A Wilcoxon matched pairs signed-rank test was further performed to determine whether there is a significant difference in the test results between the experimental and the control group. The Wilcoxon signed-rank test showed that there is no statistically significant difference between the two groups $(Z=-0.339, p=0.734)$. In fact, the Median for both groups is 16.50 , suggesting that participants performed very similarly.

Finally, a Kruskal Wallis test was additionally used to determine whether participants' previous experience with accessibility design affected the results of the comparative study. The Kruskal-Wallis $\mathrm{H}$ test showed that whilst the experience has had an effect on the performance of the participants, this was not statistically significant $(p=.096$ for the experimental group and $p=0.226$ for the control group).

\subsubsection{User Engagement results}

Overall, the participants found GATE considerably more engaging than going through the online documentation. Accordingly, this section presents the analysis of the results of the UES survey.

Figure 9 shows the box-plot of the UES surveys for the experimental group (GATE) and the control group (WCAG documentation). Participants rated GATE considerably higher compared to the online documentation in the UES survey, suggesting that the group who used GATE were more engaged in comparison. Table 5 presents the descriptive data of the engagement survey between the experimental and control groups. As can be observed, the mean of the engagement survey for the experimental group is higher $(\mathrm{M}=90.6)$ compared to the mean for the control group $(M=48.2)$. 


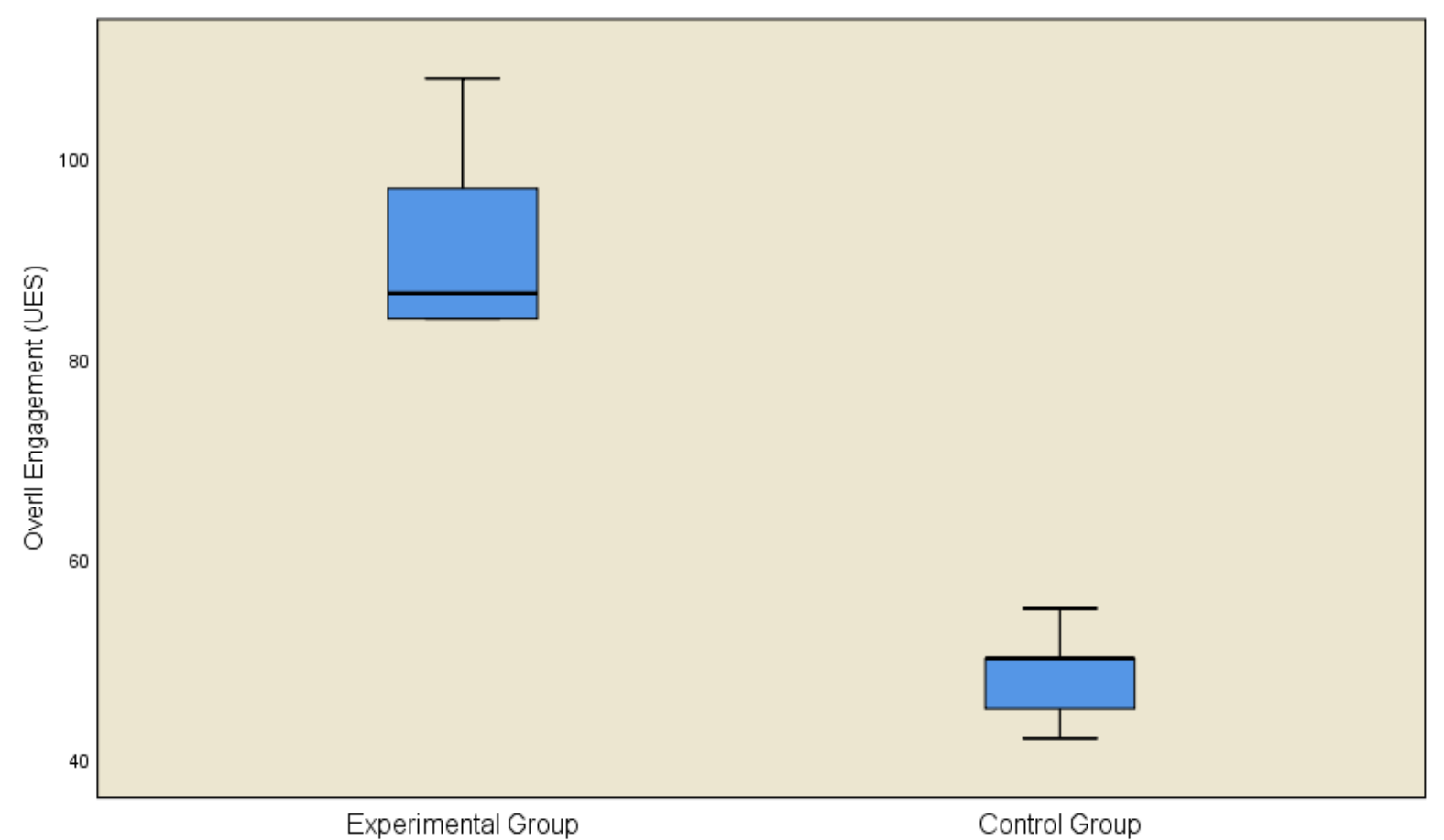

Figure 9. Box-plot for the overall engagement in the experimental group (GATE) and the control group (WCAG documentation) in \%, using the UES survey.

Table 5. Descriptive data for UES survey comparing engagement between the experimental group (GATE) and the control group (WCAG documentation)

\begin{tabular}{lllllll} 
& $\mathbf{N}$ & Min & Max & Sum & Mean & SD \\
\hline $\begin{array}{l}\text { Experimental } \\
\text { Group }\end{array}$ & 10 & 84 & 108 & 906 & 90.6 & 8.79 \\
Control Group & 10 & 42 & 55 & 482 & 48.2 & 3.94 \\
\hline $\begin{array}{l}\text { Valid N } \\
\text { (listwise) }\end{array}$ & 10 & & & & &
\end{tabular}

A Wilcoxon matched pairs signed-rank test was further performed to determine whether there is a significant difference in the engagement levels between the experimental and the control groups. The test showed that participants' engagement level was significantly different between the experimental group and the control group $(Z=-2.810, p=0.005)$. The Median engagement for the experimental group is 86.50 and for the control group is 50.00 , suggesting that participants from the experimental group were more engaged compared to the control group. The reliability analysis of this surveys showed that the Cronbach alpha $(\alpha=0.861$ for Experimental group and $\alpha=0.816$ for Control Group) is at an acceptable level for this study. Overall, KMO sample adequacy measure for Experimental Group is 0.96 and for Control Group is 0.89 . 
Existence of any gender differences in usability perception and engagement was also investigated. The Wilcoxon-Mann-Whitney test showed that there is no statistically significant difference between the engagement levels in male and female participants in the experimental group $(p=.741)$. Similarly, the Wilcoxon-MannWhitney test showed no significant difference between the engagement levels in the control group ( $p=.659)$. Finally, a Kruskal Wallis test was used to determine whether participants' previous experience with accessibility design affected the engagement with GATE. The Kruskal-Wallis $\mathrm{H}$ test showed that there was no statistically significant difference in engagement between those who had less experience with accessibility design and the more experienced $(p=.520)$.

\subsubsection{PSSUQ survey results}

This section presents and discusses the results of our post-study questionnaire carried out in Stage iii which are supported by selected participant comments recorded through the think-aloud approach. The PSSUQ measured perceptions of Overall System Satisfaction (Item 1), System Quality (Items 2-10), Information Quality (Items 11-15), and Interface Quality (Items 16-19) on a 1 (Strongly disagree) to 7 (Strongly agree) point Likert scale. The average of each of the above dimensions was taken in order to obtain an overall satisfaction score according to Lewis (Lewis, 2002, 1992).

As presented in Figure 10, GATE was perceived overall as a highly satisfactory system. All responses have averaged above the chance line (value 4 would be the average for a 1-7 scale). Overall System Satisfaction (Item 1) had a high satisfaction (Mean=5.75, SD=0.62), which indicates that the system was received well by the participants. The reliability analysis of this surveys showed that the Cronbach alpha $(\alpha=0.850)$ is at an acceptable level. Overall, KMO sample adequacy measure is 0.89 . 


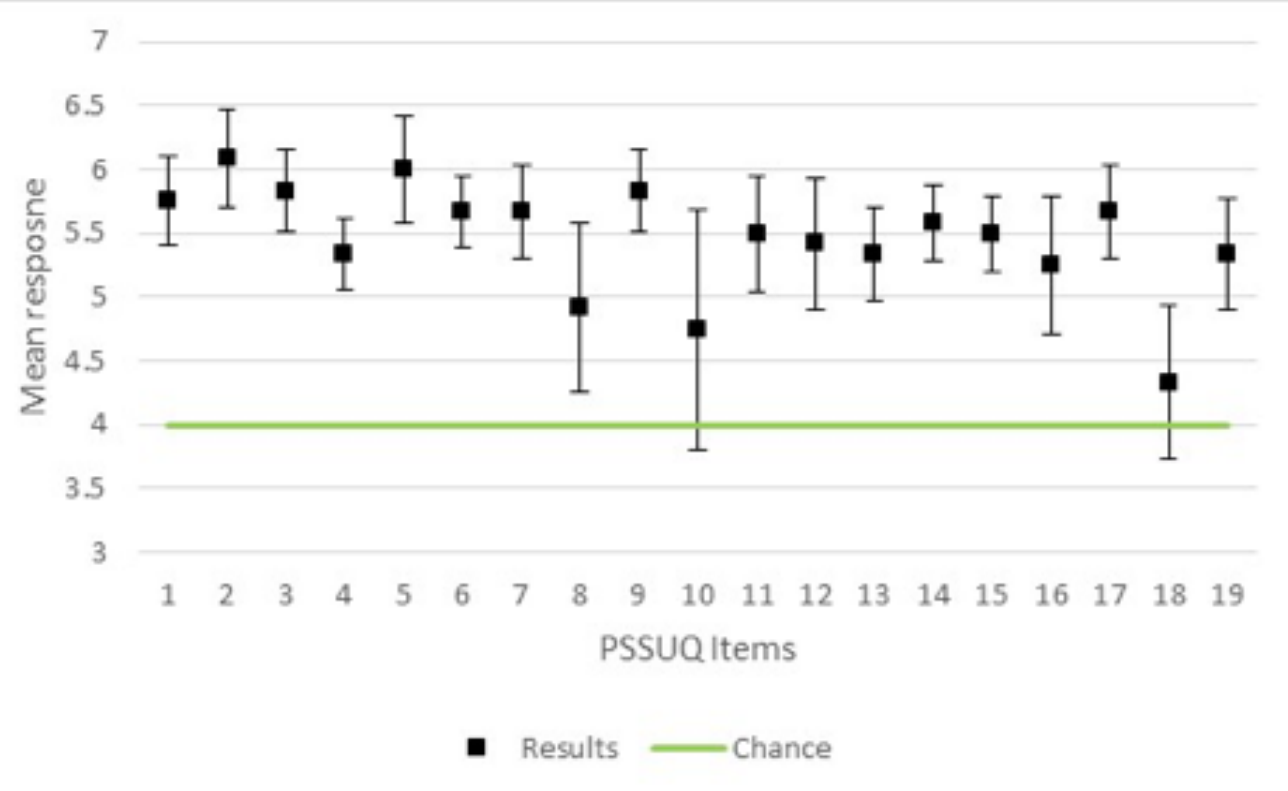

Figure 10. Wilson confidence interval of PSSUQ.

The System Quality perception (Items 2-10) is also strongly averaging above 5 with high confidence in the responses. However, Item 4 "I was able to complete the tasks and scenarios quickly using this system" received the lower satisfaction (Mean=5.33, $S D=0.49$ ), which indicates that some participants found certain challenges difficult and had to spend more time on them than they had expected. Notably, the 'Keyboards Accessible' level was identified as challenging during the think-aloud approach, which considering the context, is reasonable. Item 8 "I believe I could become productive quickly using this system" received a high error margin as the deviation of responses was 1.16. A number of participants, whilst acknowledging that GATE would increase their engagement with the WCAG, did not feel this engagement would increase their productivity. This is an interesting point and would rely on participants' perception of productivity, whether they consider productivity as the quantity of the work, or the quality of the work performed adhering to the guidelines. The Information Quality (Items 11-15) responses averaged above 4.75, which again shows a satisfactory perception by the participants. However, Item 11 "The information (such as on-line help, on-screen messages and other documentation) provided with this system was clear" received the lowest satisfaction in the category (Mean=4.75, SD=1.65). The mixed responses in this category could be related to the communication with the Assistive Robot. Comments revealed that the participants who communicated more with the Assistive Robot were satisfied whilst the lower communication led to lower satisfaction. We plan to encourage the 
communication more through prompting the player more into conversations during gameplay.

Finally, the Interface Quality (Items 16-19) received high satisfaction responses (overall average above 5). Participants were satisfied with the quality of the interaction and indicated that they were able to effectively perform all the tasks and compete the scenarios. Item 18 "This system has all the functions and capabilities I expect it to have" did however receive a lower satisfaction (Mean=4.33, SD=1.07). This could be attributed to the lack of auditory feedback. In fact, during the thinkaloud approach, participants identified audio as a weakness in the system. While the game has background music and atmospheric and interaction sound effects (e.g. opening doors, pressing buttons), the participants identified that they would like to also have audio feedback such as sounds effects when objects are picked up, or when a challenge is achieved. They would also have liked voice-over for messages communicated by the Assistive Robot.

\section{Concluding discussion}

This section discusses the overall findings and presents the identified implications and contributions of this work.

\subsection{Overall findings}

In this paper we introduced GATE - a novel proof-of-concept serious game which can assist towards the design of accessible user interfaces. Our game was developed in order to assist designers better engage with the WCAG through play in a user-friendly manner. Two studies were reported which informed the design and evaluated the game for its effectiveness, user engagement, and user satisfaction. The results highlighted a general consensus that our game was a usable system that ranked high in terms of user engagement whilst retaining effectiveness similar to existing online documentation.

Specifically, our comparative user study revealed that there is no statistically significant difference between the performance of the two groups (experimental and control) in identifying accessibility issues. On the other hand, our findings showed that user engagement levels between the two groups were statistically significantly different with participants finding GATE considerably more engaging than going through the online documentation. This is an encouraging finding as it demonstrates 
that GATE allows for achieving the same end result, but in a more engaging manner, which is in line with our hypothesis.

Similarly, the post-study results measured through the PSSUQ demonstrated that overall user satisfaction was averaging above 4.75 across all measured items. PSSUQ further revealed that the quality of the provided information (Item 11) could be improved if the interaction with the Assistive Robot is further enhanced. This is an interesting observation that points to a positive relationship between depth of interaction and information quality. However, it is necessary that the perceived efficacy of GATE will be explored further in a larger-scale study. The full investigation of the effectiveness of GATE therefore constitutes part of our future endeavours.

\subsection{Implications and contributions}

This section summarises the findings and insights from this research work. Accordingly, the main contributions of this work are: a) improving designer engagement with WCAG through a novel serious game, b) an approach to integrate WCAG into games, c) discussion of how our findings could be applied to the design of similar games for designers. These are elaborated below.

Enjoyment improves engagement with WCAG. We established that lack of knowledge is an important factor in the case of implementing the WCAG. In this work, by proposing a proof-of-concept game for the purpose of improving engagement with the WCAG, it is possible to moderate the lack of knowledge that designers are faced with and enable them to know what they should consider when designing accessible solutions. However, in order to facilitate engagement, research has shown that this is influenced by how satisfying a game is for a player (Merhi, 2016). Customisation has also been shown to influence players' enjoyment (Teng, 2017). Accordingly, our Study 2 results indicate that GATE's Overall System Satisfaction was high (Mean=5.75, SD=0.62), while our highly tailored game, as shown through Study 1 , adds another dimension of fulfilment for players. Our comparative user study further confirmed that GATE is significantly more engaging compared to existing online documentation $(Z=-2.810, p=0.005$, experimental group $\mathrm{M}=90.6$; control group $\mathrm{M}=48.2$ ). Our studies' results, therefore, point to an equally high level of engagement with the game. Interestingly, participants commented that they would appreciate a higher level of immersion in the game (GS7) indicating the importance of emotional engagement to designers. Indeed, 
Dominguez et al. (2013) found that emotional engagement is crucial for successful games. We can therefore surmise that increased engagement can lead to enhanced work performance. Research has in fact shown that this can be achieved as a result of a number of mechanisms and components, such as work enjoyment and intrinsic work motivation (Alessandri et al., 2015). Our findings are in line with the above, as GATE has shown to both improve engagement with WCAG through enjoyment (Study 2), as well as to cater for intrinsic motivation (Study 1). It is therefore recommended that enjoyment and intrinsic motivation should be key ingredients in engaging designers in similar activities.

\section{A serious game can turn complex work activities into informative play} activities for designers. The foundation of GATE is turning a laborious, yet important workplace activity i.e. accessibility design using the WCAG, into a playful activity. Our findings from the comparative user study indicated that designers found the activity of engaging with WCAG through play as an attractive approach. This is in line with previous findings that employees enjoy work activities that include elements of play (Petelczyc et al., 2018). In our work, we found that turning accessibility design into a play activity could be enabled through certain game mechanics that are shown to be most appealing to designers. Specifically, participants highlighted in their comments that autonomy implemented as an ability to roam freely within the game environment helped them feel engaged and kept the game fresh. Exploration and learning are therefore important elements of play to designers and should be investigated by further studies based on appropriate behavioural theories. Similarly, participants identified that GATE would benefit from the ability to provide players with flexible controls and additional menus. This was also identified from the results of the PSSUQ, and specifically, in Item 18 which indicated that participants would prefer additional functions and capabilities. Indeed, past research indicated that customisation is related to personal control (Turkay and Adinolf, 2010) and the feeling of "ownership" (Ondrejka, 2004), which are elements that designers identify within games according to our findings. It is suggested that the aforementioned game mechanics should be considered when designing similar gameful experiences for designers.

No "one size fits all" user type for designers in games. Players are typically categorised based on motivation (Yee, 2006) and enjoyment (Hunicke et al., 2004). 
This premise has led to numerous player type preference models that are currently reported in the literature, but they all point to two common mechanics; achievement and socialisation (Zichermann and Linder, 2010), which are both aspects of intrinsic motivation. Results from our Study 1 confirm this, as we found that designers are intrinsically motivated types who are mostly driven by challenges ("Achiever"), exploration ("Free Spirit"), altruism ("Philanthropist"), and social connections ("Socializer"). Accordingly, we found that game mechanics such as challenges, nonlinear gameplay, achievements, unlockable content, knowledge sharing, and social discovery can be used to this effect when designing engaging games for designers. However, our findings further point to the fact that there is no single, optimal user type appealing to designers. In fact, participants indicated that they identified themselves with all six user types in the HEXAD Framework. It is therefore suggested that design for designer populations should not only consider the intrinsic types, but extrinsic types ("Player") and types looking to influence a game ("Disruptor") must also be attended to by ensuring that they can be transitioned to more engaged types. In GATE, the latter type has been addressed through an Anarchic gameplay mechanic.

\subsection{Limitations and future work}

Our findings present a number of limitations that need to be considered. We acknowledge that the relatively small number of participants in our studies may have an impact on the generalisation of our findings. However, given the limited existing efforts in this research area, the reported findings can be considerably useful as they offer significant insights and could be used as an important point of reference for future efforts. Overall, our findings provide a positive indication towards the acceptance of the proof-of-concept game by designers. However, the lack of audio and auditory feedback was perceived as a weakness, and it is therefore unclear what impact the inclusion of audio would have to the user experience and whether it would help designers feel more immersed. We also acknowledge that we used two types of questionnaires to measure user engagement and user satisfaction, respectively. Employing additional methods could lead to more insights. Finally, while both user engagement and user satisfaction were evident from our findings, GATE's impact on increasing productivity and awareness were not investigated. Accordingly, our findings present two main avenues for future work. First, a further 
longevity study is needed to fully assess the above. This would require a well thought out design process underpinned by appropriate theory. Second, the recently published WCAG 2.1 version of the guidelines will be considered and incorporated into GATE, as at the time of development those were not available.

Overall, this work can contribute to ongoing efforts in adopting good accessibility practices when designing ICT products and services for all, which is not only required by law, but it also provides equal access and equal opportunities to people with disabilities and therefore help avoid social exclusion.

\section{Acknowledgements}

We would like to thank all volunteers who participated in our studies and contributed to the design and evaluation of GATE.

Disclosure of interest: The authors report no conflict of interest.

Funding: This research did not receive any specific grant from funding agencies in the public, commercial, or not-for-profit sectors.

Data availability statement: The data that support the findings of the reported studies are available from the corresponding author, upon reasonable request.

\section{References}

AbilityNet, 2017. Digital Accessibility Resources [WWW Document]. URL https://www.abilitynet.org.uk/expert-resources/web-accessibility-resources (accessed 3.12.18).

Abt, C.C., 1987. Serious games. University press of America.

Alessandri, G., Borgogni, L., Schaufeli, W.B., Caprara, G.V., Consiglio, C., 2015. From Positive Orientation to Job performance: The Role of Work Engagement and Self-efficacy Beliefs. J. Happiness Stud. 16, 767-788. https://doi.org/10.1007/s10902-014-9533-4

Aleven, V., Myers, E., Easterday, M., Ogan, A., 2010. Toward a Framework for the Analysis and Design of Educational Games, in: 2010 Third IEEE International Conference on Digital Game and Intelligent Toy Enhanced Learning. IEEE, pp. 69-76. https://doi.org/10.1109/DIGITEL.2010.55

Aubert, A.H., Bauer, R., Lienert, J., 2018. A review of water-related serious games to specify use in environmental Multi-Criteria Decision Analysis. Environ. Model. Softw. 105, 64-78.

Brondi, R., Alem, L., Avveduto, G., Faita, C., Carrozzino, M., Tecchia, F., Bergamasco, M., 2015. Evaluating the impact of highly immersive technologies and natural interaction on player engagement and flow experience in games, in: Lecture Notes in Computer Science (Including Subseries Lecture Notes in Artificial Intelligence and Lecture Notes in Bioinformatics). Springer, Cham, pp. 169-181. https://doi.org/10.1007/978-3-319-24589-8_13 
Campbell, D.T. and, Stanley, J.C., 2015. Experimental and quasi-experimental designs for research. Ravenio Books, p. 84.

Cargnin, D.J., Cordeiro D'Ornellas, M., Cervi Prado, A.L., 2015. A Serious Game for Upper Limb Stroke Rehabilitation Using Biofeedback and Mirror-Neurons Based Training, in: Studies in Health Technology and Informatics. pp. 348-352. https://doi.org/10.3233/978-1-61499-564-7-348

CEUD, 2013. Irish National IT Accessibility Guidelines [WWW Document]. Univers. Des. URL http://universaldesign.ie/Technology-ICT//rish-National-ITAccessibility-Guidelines/ (accessed 3.12.18).

Charles, D., Black, M., 2004. Dynamic Player Modelling: A Framework for Playercentred Digital Games. Proc. 5th Int. Conf. Comput. Games Artif. Intell. Des. Educ. Microsoft, 29-35. https://doi.org/10.1.1.579.6671

Chisholm, W., Kasday, L., 2005. Evaluation, Repair, and Transformation Tools for Web Content Accessibility.

Clark, J., 2006. To Hell with WCAG 2: A List Apart.

Connolly, T.M., Boyle, E.A., MacArthur, E., Hainey, T., Boyle, J.M., 2012. A systematic literature review of empirical evidence on computer games and serious games. Comput. Educ. 59, 661-686.

Cooper, A., 1999. The Inmates are Running the Asylum. Sams, pp. 17-17. https://doi.org/10.1007/978-3-322-99786-9_1

Cowley, B., Charles, D., Black, M., Hickey, R., 2013. Real-time rule-based classification of player types in computer games. User Model. User-Adapted Interact. 23, 489-526. https://doi.org/10.1007/s11257-012-9126-z

Crookall, D., 2010. Serious games, debriefing, and simulation/gaming as a discipline. Simul. Gaming 41, 898-920.

Daylamani-Zad, D., Agius, H., Angelides, M.C., 2018. Reflective agents for personalisation in collaborative games. Artif. Intell. Rev. https://doi.org/10.1007/s10462-018-9665-8

Daylamani-Zad, D., Angelides, M.C., Agius, H., 2014. Collaboration through Gaming, in: Handbook of Digital Games. John Wiley \& Sons, Inc., Hoboken, NJ, USA, pp. 235-273. https://doi.org/10.1002/9781118796443.ch9

Daylamani-Zad, D., Angelides, M.C.M.C., Agius, H., 2016. Lu-Lu: A framework for collaborative decision making games. Decis. Support Syst. 85, 49-61. https://doi.org/10.1016/j.dss.2016.02.011

Deci, E.L., Koestner, R., Ryan, R.M., 1999. A meta-analytic review of experiments examining the effects of extrinsic rewards on intrinsic motivation. Psychol. Bull. https://doi.org/10.1037/0033-2909.125.6.627

DeFalco, J.A., Rowe, J.P., Paquette, L., Georgoulas-Sherry, V., Brawner, K., Mott, B.W., Baker, R.S., Lester, J.C., 2018. Detecting and addressing frustration in a serious game for military training. Int. J. Artif. Intell. Educ. 28, 152-193.

Deterding, S., 2015. The Lens of Intrinsic Skill Atoms: A Method for Gameful Design. Human-Computer Interact. 30, 294-335.

Disability Rights Commission, 2004. The Web - Access and Inclusion for Disabled People.

Domínguez, A., Saenz-De-Navarrete, J., De-Marcos, L., Fernández-Sanz, L., Pagés, C., Martínez-Herráiz, J.J., 2013. Gamifying learning experiences: Practical implications and outcomes. Comput. Educ. 63, 380-392.

https://doi.org/10.1016/j.compedu.2012.12.020

Ferro, L.S., Walz, S.P., Greuter, S., 2013. Towards personalised, gamified systems, in: Proceedings of The 9th Australasian Conference on Interactive 
Entertainment Matters of Life and Death - IE '13. ACM Press, New York, New York, USA, pp. 1-6. https://doi.org/10.1145/2513002.2513024

Flood, S., Cradock-Henry, N.A., Blackett, P., Edwards, P., 2018. Adaptive and interactive climate futures: Systematic review of 'serious games' for engagement and decision-making. Environ. Res. Lett. 13, 63005.

Göbel, S., Wendel, V., Ritter, C., Steinmetz, R., 2010. Personalized, Adaptive Digital Educational Games Using Narrative Game-Based Learning Objects.

Edutainment 2010 438-445. https://doi.org/10.1007/978-3-642-14533-9_45

Grammenos, D., 2008. Game over: Learning by dying, in: Proceeding of the TwentySixth Annual $\mathrm{CHI}$ Conference on Human Factors in Computing Systems - $\mathrm{CHI}$ '08. ACM Press, New York, New York, USA, p. 1443. https://doi.org/10.1145/1357054.1357281

Halan, S., Rossen, B., Cendan, J., Lok, B., 2010. High score! - Motivation strategies for user participation in virtual human development, in: Lecture Notes in Computer Science (Including Subseries Lecture Notes in Artificial Intelligence and Lecture Notes in Bioinformatics). Springer, Berlin, Heidelberg, pp. 482-488. https://doi.org/10.1007/978-3-642-15892-6_52

Hersh, M., 2017. Classification framework for ICT-based learning technologies for disabled people. Br. J. Educ. Technol. 48, 768-788. https://doi.org/10.1111/bjet.12461

Holz, H., Brandelik, K., Beuttler, B., Brandelik, J., Ninaus, M., 2018. How to train your syllable stress awareness. Int. J. Serious Games 5, 37-59.

Hunicke, R., LeBlanc, M., Zubek, R., 2004. MDA: A Formal Approach to Game Design and Game Research. Work. Challenges Game Al 1-4. https://doi.org/10.1.1.79.4561

IBM Research, n.d. IBM aDesigner [WWW Document]. URL https://www03.ibm.com/able/dwnlds/aDesigner_accessible.pdf (accessed 3.13.18).

Karpinskyj, S., Zambetta, F., Cavedon, L., 2014. Video game personalisation techniques: A comprehensive survey. Entertain. Comput. https://doi.org/10.1016/j.entcom.2014.09.002

Katerine Marceles, V., Burbano, C.L., 2018. Characterization of the Serious Games Applied to the Historical Heritage, in: Telematics and Computing: 7th International Congress, WITCOM 2018, Mazatlán, Mexico, November 5-9, 2018, Proceedings. Springer, p. 135.

Katsaounidou, A., Vrysis, L., Kotsakis, R., Dimoulas, C., Veglis, A., 2019. MAthE the Game: A Serious Game for Education and Training in News Verification. Educ. Sci. 9, 155. https://doi.org/10.3390/educsci9020155

Kelle, S., Henka, A., Zimmermann, G., 2015. A Persona-based Extension for Massive Open Online Courses in Accessible Design. Procedia Manuf. 3, 36633668. https://doi.org/10.1016/j.promfg.2015.07.772

Lamb, R.L., Annetta, L., Firestone, J., Etopio, E., 2018. A meta-analysis with examination of moderators of student cognition, affect, and learning outcomes while using serious educational games, serious games, and simulations. Comput. Human Behav. 80, 158-167.

Lambert, S., 2018. Designing For Accessibility And Inclusion [WWW Document]. URL https://www.smashingmagazine.com/2018/04/designing-accessibilityinclusion/ (accessed 3.7.19).

Lazar, J., Dudley-Sponaugle, A., Greenidge, K.D., 2004. Improving web accessibility: A study of webmaster perceptions. Comput. Human Behav. 20, 269-288. https://doi.org/10.1016/j.chb.2003.10.018 
Lewis, J.R., 2002. Psychometric Evaluation of the PSSUQ Using Data from Five Years of Usability Studies. Int. J. Hum. Comput. Interact. 14, 463-488. https://doi.org/10.1080/10447318.2002.9669130

Lewis, J.R., 1992. Psychometric Evaluation of the Post-Study System Usability Questionnaire: The PSSUQ. Proc. Hum. Factors Ergon. Soc. Annu. Meet. 36, 1259-1260. https://doi.org/10.1177/154193129203601617

Lu, A.S., Baranowski, T., Thompson, D., Buday, R., 2012. Story Immersion of Videogames for Youth Health Promotion: A Review of Literature. Games Health J. 1, 199-204. https://doi.org/10.1089/g4h.2011.0012

Marczewski, A., 2015. Even ninja monkeys like to play: gamification, game thinking \&amp; motivational design. Gamified UK.

Martin, B., Hanington, B.M., 2012. Universal methods of design : 100 ways to research complex problems, develop innovative ideas, and design effective solutions. Rockport Publishers.

McGregor, C., Bonnis, B., Stanfield, B., Stanfield, M., 2016. Design of the ARAIG haptic garment for enhanced resilience assessment and development in tactical training serious games, in: 2016 IEEE 6th International Conference on Consumer Electronics-Berlin (ICCE-Berlin). IEEE, pp. 214-217.

Meijer, H.A., Graafland, M., Goslings, J.C., Schijven, M.P., 2018. Systematic Review on the Effects of Serious Games and Wearable Technology Used in Rehabilitation of Patients With Traumatic Bone and Soft Tissue Injuries. Arch. Phys. Med. Rehabil. 99, 1890-1899.

Merhi, M.I., 2016. Towards a framework for online game adoption. Comput. Human Behav. 60, 253-263. https://doi.org/10.1016/J.CHB.2016.02.072

Mi, N., Cavuoto, L.A., Benson, K., Smith-Jackson, T., Nussbaum, M.A., 2014. A heuristic checklist for an accessible smartphone interface design. Univers. Access Inf. Soc. 13, 351-365. https://doi.org/10.1007/s10209-013-0321-4

Michael, D.R., Chen, S.L., 2005. Serious games: Games that educate, train, and inform. Muska \& Lipman/Premier-Trade.

Molnar, A., 2019. Antimicrobial Resistance Awareness and Games. Trends Microbiol. 27, 1-3.

Myers, I., McCaulley, M., 1985. Manual: A Guide To The Development And Use Of The Myers-Briggs Type Indicator. Consulting Psychologists Press.

O'Brien, H.L., Toms, E.G., 2010. The development and evaluation of a survey to measure user engagement. J. Am. Soc. Inf. Sci. Technol. 61, 50-69. https://doi.org/10.1002/asi.21229

Oliveri, S., Mainetti, R., Gorini, A., Cutica, I., Candiani, G., Borghese, N.A., Pravettoni, G., 2018. Serious Games for Improving Genetic Literacy and Genetic Risk Awareness in the General Public: Protocol for a Randomized Controlled Trial. JMIR Res. Protoc. 7.

Ondrejka, C.R., 2004. Escaping the Gilded Cage: User Created Content and Building the Metaverse. New York Law Sch. Law Rev. 49, 81-101.

Orji, R., Mandryk, R.L., Vassileva, J., Gerling, K.M., 2013. Tailoring persuasive health games to gamer type, in: Proceedings of the SIGCHI Conference on Human Factors in Computing Systems - CHI '13. ACM Press, New York, New York, USA, p. 2467. https://doi.org/10.1145/2470654.2481341

Pandit, S., Vaddepalli, S., Tupsamudre, H., Banahatti, V., Lodha, S., 2018. PHISHYA Serious Game to Train Enterprise Users on Phishing Awareness, in:

Proceedings of the 2018 Annual Symposium on Computer-Human Interaction in Play Companion Extended Abstracts. ACM, pp. 169-181. 
Papaioannou, T.G., Hatzi, V., Koutsopoulos, I., 2018. Optimal design of serious games for consumer engagement in the smart grid. IEEE Trans. Smart Grid 9, 1241-1249.

Paraskevopoulos, I.T., Tsekleves, E., Craig, C., Whyatt, C., Cosmas, J., 2014. Design guidelines for developing customised serious games for parkinson's disease rehabilitation using bespoke game sensors. Entertain. Comput. 5, 413424. https://doi.org/10.1016/j.entcom.2014.10.006

Pavlus, J., 2010. The Game of Life. Sci. Am. 303, 43-44. https://doi.org/10.1038/scientificamerican1210-43

Petelczyc, C.A., Capezio, A., Wang, L., Restubog, S.L.D., Aquino, K., 2018. Play at Work: An Integrative Review and Agenda for Future Research. J. Manage. 44, 161-190. https://doi.org/10.1177/0149206317731519

Pourabdollahian, B., Taisch, M., Kerga, E., 2012. Serious games in manufacturing education: Evaluation of learners' engagement. Procedia Comput. Sci. 15, 256265.

Ryan, R.M., Rigby, C.S., Przybylski, A., 2006. The Motivational Pull of Video Games: A Self-Determination Theory Approach. Motiv. Emot. 30, 344-360. https://doi.org/10.1007/s11031-006-9051-8

Scott, M.J., Spyridonis, F., Ghinea, G., 2015. Designing for designers: Towards the development of accessible ICT products and services using the VERITAS framework. Comput. Stand. Interfaces 42, 113-124. https://doi.org/10.1016/j.csi.2015.05.004

Section508.gov, 1998. Section 508 Law and Related Laws and Policies [WWW Document]. Sect. 508 Rehabil. Act 1973. URL https://section508.gov/content/learn/laws-and-policies (accessed 3.12.18).

Shneiderman, B., 2004. Designing for fun. interactions 11, 48. https://doi.org/10.1145/1015530.1015552

Sorace, S., Quercia, E., La Mattina, E., Patrikakis, C.Z., Bacon, L., Loukas, G., Mackinnon, L., 2018. Serious Games: An Attractive Approach to Improve Awareness. Community-Oriented Polic. Technol. Innov. 1-9.

Spyridonis, F., Daylamani-Zad, D., Paraskevopoulos, I.T., 2017. The gamification of accessibility design: A proposed framework, in: 2017 9th International Conference on Virtual Worlds and Games for Serious Applications, VS-Games 2017 - Proceedings. https://doi.org/10.1109/VS-GAMES.2017.8056606

Spyridonis, F., Moschonas, P., Touliou, K., Tsakiris, A., Ghinea, G., 2014. Designing accessible ICT products and services, in: Proceedings of the 2014 International Working Conference on Advanced Visual Interfaces - AVI '14. ACM Press, pp. 113-116.

Stettina, C.J., Offerman, T., De Mooij, B., Sidhu, I., 2018. Gaming for agility: using serious games to enable agile project \& portfolio management capabilities in practice, in: 2018 IEEE International Conference on Engineering, Technology and Innovation (ICE/ITMC). IEEE, pp. 1-9.

Stiegler, A., Zimmermann, G., 2015. Gamification and Accessibility. Springer, Cham, pp. 145-154. https://doi.org/10.1007/978-3-319-20892-3_15

Stiegler, A., Zimmermann, G., 2014. Gamification in the Development of Accessible Software. Springer, Cham, pp. 171-180. https://doi.org/10.1007/978-3-31907437-5_17

Suits, B., 2005. The grasshopper: games, life and utopia. Broadview Press.

Susi, T., Johannesson, M., Backlund, P., 2007. Serious games-An overview. IKI Tech. Reports HS-IKI-TR-07-001 28. https://doi.org/10.1.1.105.7828 
Sykes, J., Federoff, M., 2006. Player-centred game design, in: CHI '06 Extended Abstracts on Human Factors in Computing Systems - CHI EA '06. ACM Press, New York, New York, USA, p. 1731. https://doi.org/10.1145/1125451.1125774

Teng, C.-I., 2017. Strengthening Loyalty of Online Gamers: Goal Gradient Perspective. Int. J. Electron. Commer. 21, 128-147. https://doi.org/10.1080/10864415.2016.1204195

Tondello, G.F., Wehbe, R.R., Diamond, L., Busch, M., Marczewski, A., Nacke, L.E., 2016. The Gamification User Types Hexad Scale, in: Proceedings of the 2016 Annual Symposium on Computer-Human Interaction in Play - CHI PLAY '16. ACM Press, New York, New York, USA, pp. 229-243. https://doi.org/10.1145/2967934.2968082

Turkay, S., Adinolf, S., 2010. Free to be me: A survey study on customization with World of Warcraft and City of Heroes/Villains players, in: Procedia - Social and Behavioral Sciences. Elsevier, pp. 1840-1845. https://doi.org/10.1016/j.sbspro.2010.03.995

UK Government, 2010. Equality Act 2010. Statute Law Database.

University of Cambridge, 2017. Impairment simulator software [WWW Document]. URL http://www.inclusivedesigntoolkit.com/simsoftware/simsoftware.html (accessed 3.13.18).

WebAIM, 2018. Survey of Web Accessibility Practitioners \#2 Results [WWW Document]. URL https://webaim.org/projects/practitionersurvey2/ (accessed 2.28.19).

Yasin, A., Liu, L., Li, T., Fatima, R., Jianmin, W., 2018. Improving software security awareness using A serious game. IET Softw.

Yee, N., 2006. Motivations for Play in Online Games. CyberPsychology Behav. 9, 772-775. https://doi.org/10.1089/cpb.2006.9.772

Zichermann, G., Linder, J., 2010. Game Based Marketing: Inspire Customer Loyalty Through Rewards, Challenges, and Contests. Wiley. 